\title{
A Porphyrinic Zirconium Metal-Organic Framework for Oxygen Reduction Reaction: Tailoring the Spacing between Active-Sites through Chain-Based Inorganic Building Units
}

Magdalena Ola Cichocka, ${ }^{\nabla}$ Zuozhong Liang, ${ }^{\nabla}$ Dawei Feng, Seoin Back, Samira Siahrostami, Xia Wang, Laura Samperisi, Yujia Sun, Hongyi Xu, Niklas Hedin, Haoquan Zheng, * Xiaodong Zou, HongCai Zhou* and Zhehao Huang*

Table of Contents:

Section 1. Materials and instrumentation

Section 2. Ligand synthesis

Section 3. Synthesis of PCN-226 (M)

Section 4. Structure characterization of PCN-226(Cu)

Section 5. Electrochemical analysis of PCN-226(Co)

Section 6. Theoretical calculation 


\section{Section 1. Materials and Methods}

\section{Materials.}

Methyl 4-formylbenzoate was purchased from Oakwood Products. Inc. Pyrrole, propionic acid, $N, N-$ diethylformamide (DEF), iron(II) chloride tetrahydrate $\left(\mathrm{FeCl}_{2} \cdot 4 \mathrm{H}_{2} \mathrm{O}\right)$, cobalt (II) chloride hexahydrate $\left(\mathrm{CoCl}_{2} \cdot 6 \mathrm{H}_{2} \mathrm{O}\right)$, nickel (II) chloride hexahydrate $\left(\mathrm{NiCl}_{2} \cdot 6 \mathrm{H}_{2} \mathrm{O}\right)$, and copper (II) chloride hexahydrate $\left(\mathrm{CuCl}_{2} \cdot 2 \mathrm{H}_{2} \mathrm{O}\right)$ were from Alfa Aesar. Benzoic acid, $N, N$-dimethylformamide (DMF), acetone, and zinc (II) chloride $\left(\mathrm{ZnCl}_{2}\right.$, anhydrous) were purchased from Sigma-Aldrich. 5,10,15,20-Tetrakis(4methoxycarbonylphenyl)porphyrin (TPPCOOMe) was prepared according to procedures described in Section S2. All the reagents and solvents were used without further purification unless otherwise mentioned.

\section{Methods.}

Transmission electron microscopy (TEM). For electron diffraction study using TEM, the sample of PCN-226 stocking in dimethyl formamide (DMF) was prepared by crushing the powder and dispersing in ethanol. Then, a droplet of the suspension was transferred to a carbon-film copper grid. Continuous rotation electron diffraction (cRED) measurement was performed on a JEOL JEM2100 TEM at $200 \mathrm{kV}$ using a Timepix pixel detector QTPX-262k (512 x 512 pixels, pixel size $55 \mu \mathrm{m}$, Amsterdam Sci. Ins.). Thin slices of the PCN-226 sample for high-resolution transmission electron microscopy (HRTEM) analysis was prepared by using an ultramicrotome. A through-focus series of HRTEM images were taken along the $b$-axis of PCN-226 on a JEOL JEM2100F microscope operated at $200 \mathrm{kV}$ (Cs $1.0 \mathrm{~mm}$, point resolution $0.23 \mathrm{~nm}$ ) with a Gatan Ultrascan 1000 CCD camera (resolution 2,048 $\times 2,048$ pixels, pixel size $14 \mu \mathrm{m}$ ) under low-dose conditions. The structure projection was reconstructed by using QFocus software ${ }^{1}$.

Scanning electron microscopy (SEM). SEM images were performed using a JEOL JSM-7401F with a field emission scanning electron microscope capable of generating and collecting high-resolution and low-vacuum images. The field emission gun assembles with a Schottky emitter source. The images were obtained at an accelerating voltage of $1.0 \mathrm{kV}$, with beam current of $20 \mu \mathrm{A}$.

Powder X-ray diffraction (PXRD). PXRD patterns were recorded using PANalytical X'Pert Pro diffractometer equipped with a Pixel detector and a monochromator, using $\mathrm{Cu} \mathrm{K}_{\alpha 1}$ radiation $(\lambda=1.5406$ $\AA ̊ ㇒)$. Data was recorded using current $40 \mathrm{~mA}$, accelerating voltage $40 \mathrm{~V}$ and source silt $15 \mathrm{~mm}$.

Thermogravimetric analysis (TGA). About $10 \mathrm{mg}$ of the sample was heated on a TA Instruments Discovery TGA 5500 thermogravimetric analyzer from room temperature to $800{ }^{\circ} \mathrm{C}$ at a rate of 10 ${ }^{\circ} \mathrm{C} \cdot \mathrm{min}^{-1}$ under $\mathrm{N}_{2}$ flow of $25 \mathrm{~mL} \cdot \mathrm{min}^{-1}$.

Nitrogen sorption isotherms. Nitrogen sorption isotherms were obtained at liquid nitrogen $77 \mathrm{~K}$ using Micromeritics ASAP 2020 instrument. Before the measurements, the samples were degassed under reduced pressure $(<10 \mathrm{~Pa})$ at $150{ }^{\circ} \mathrm{C}$ for $12 \mathrm{~h}$. The surface areas were calculated by the Brunauer-EmmettTeller (BET) method using the $\mathrm{N}_{2}$ adsorption data. The relative pressures used for the BET method were selected ensuring a positive intersection with the $y$-axis and a Rouquerol transformation that increased with the relative pressure. ${ }^{1}$ Pore size distribution was estimated using non-local density functional theory (NLDFT) (using geometry of slit and $\mathrm{N}_{2} @ 77 \mathrm{~K}$ on carbon slit pores as model).

Ultraviolet-visible spectroscopy. UV-Vis spectra were obtained by using Perkin Elmer Lambda 19 UVVis spectrometer.

Fourier transform infrared (FT-IR) spectroscopy. FT-IR measurements were performed on a 
SHIMADZU IR Affinity-1 spectrometer.

\section{Inductively coupled plasma optical emission spectroscopy (ICP-OES) analysis.}

Calibration standards were prepared from certified reference standards by MEDAC Ltd. Samples were further analyzed with a Varian 720ES ICP-OES spectrometer. Resulting calibration curves have minimum $\mathrm{R}^{2}=0.9999$. Additionally, in order to maintain accuracy, quality control samples from certified reference standards and internal standards were utilized. The individual results of the triplicate samples were averaged to determine the metal concentration.

\section{X-ray photoelectron spectroscopy (XPS) analysis}

The XPS spectra were obtained with an X-ray photoelectron spectrometer (ESCALAB 250X, ThermoFischer) with $\mathrm{Al} \mathrm{Ka}$ radiation $(h v=1486.6 \mathrm{eV})$ at $12.5 \mathrm{kV}$ and $16 \mathrm{~mA}$. The charge correction was carried out based on the binding energy of C1s $(284.80 \mathrm{eV})$.

\section{Section 2. Ligand synthesis}

The tetrakis(4-carboxyphenyl)porphyrin ( $\left.\mathrm{H}_{2} \mathrm{TCPP}\right)$ ligand was purchased from Frontier Scientific. Other metal ligands (M-TCPP, $\mathrm{M}=\mathrm{Mn}, \mathrm{Fe}, \mathrm{Co}, \mathrm{Ni}, \mathrm{Cu}, \mathrm{Zn}$ ) were synthesized based on previous reports. ${ }^{2}$ Typically, they are synthesized by three steps:

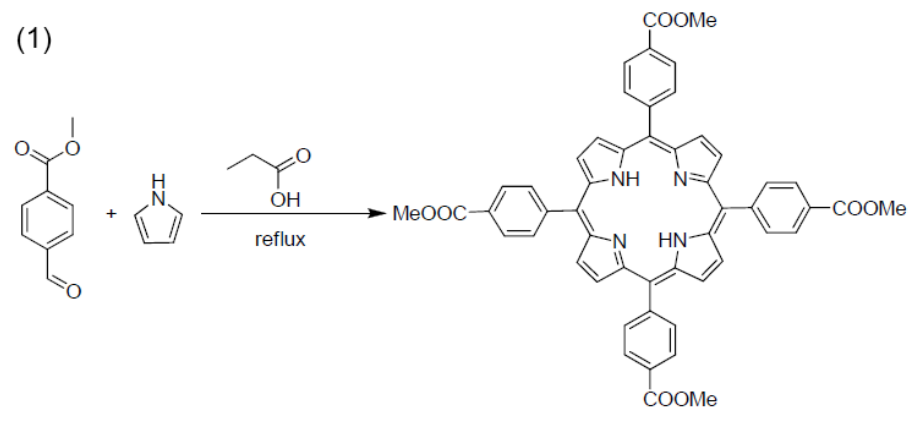

(2)

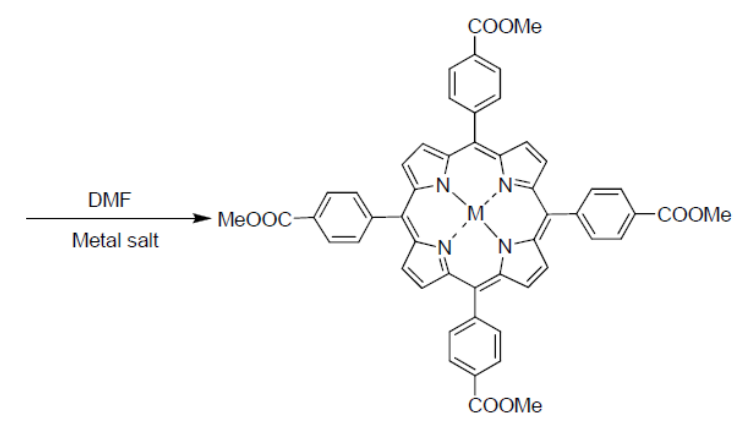

(3)

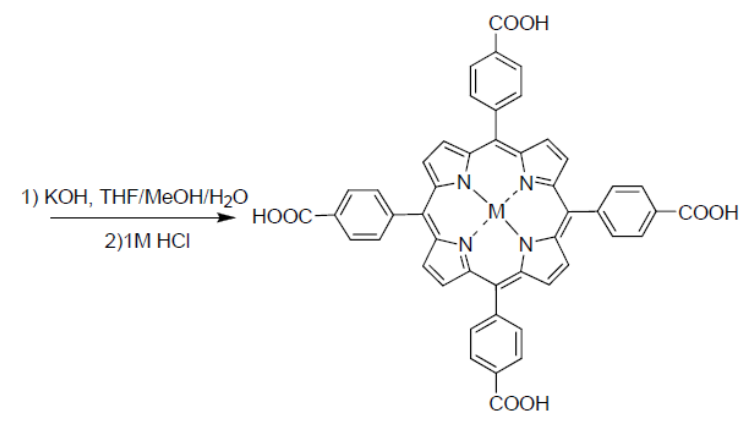

Scheme S1. Synthesis strategy for M-TCPP ligands.

1) 5,10,15,20-Tetrakis(4-methoxycarbonylphenyl)porphyrin (TPPCOOMe). 
Propionic acid $(100 \mathrm{~mL})$ was refluxed in a 500-mL three necked flask. Then, pyrrole (3.0, 0.043 mol) and methyl $p$-formylbenzoate $(6.9 \mathrm{~g}, 0.042 \mathrm{~mol})$ were added. The solution was refluxed for $12 \mathrm{~h}$ in darkness. After cooled to room temperature, crystals were collected by suction-filtration to afford purple crystals (1.9g, 2.24mmol, $21.3 \%$ yield). ${ }^{1} \mathrm{H}$ NMR (300 $\left.\mathrm{MHz} \mathrm{CDCl}_{3}\right) \delta 8.81(\mathrm{~s}, 8 \mathrm{H}), 8.43(\mathrm{~d}, 8 \mathrm{H}), 8.28(\mathrm{~d}, 8 \mathrm{H})$, $4.11(\mathrm{~s}, 12 \mathrm{H}),-2.83(\mathrm{~s}, 2 \mathrm{H})$.

\section{2) 5,10,15,20-Tetrakis(4-methoxycarbonylphenyl)porphyrin-M (MTPPCOOMe).}

[5,10,15,20-Tetrakis(4-methoxycarbonylphenyl)porphyrinato]-Cu(II). A solution of TPPCOOMe $0.854 \mathrm{~g}(1.0 \mathrm{mmol})$ and $\mathrm{CuCl}_{2} \cdot 2 \mathrm{H}_{2} \mathrm{O}(2.2 \mathrm{~g}, 12.8 \mathrm{mmol})$ in $100 \mathrm{~mL}$ of DMF was refluxed for $6 \mathrm{~h}$. After the mixture was cooled to room temperature, $150 \mathrm{~mL}$ of $\mathrm{H}_{2} \mathrm{O}$ was added. The resultant precipitate was filtered and washed with $50 \mathrm{~mL}$ of $\mathrm{H}_{2} \mathrm{O}$ for two times. The obtained solid was dissolved in $\mathrm{CHCl}_{3}$, followed by washing three times with water. The organic layer was dried over anhydrous magnesium sulfate and evaporated to afford quantitative dark red crystals.

[5,10,15,20-Tetrakis(4-methoxycarbonylphenyl)porphyrinato]-Co(II). A solution of TPPCOOMe $0.854 \mathrm{~g}(1.0 \mathrm{mmol})$ and $\mathrm{CoCl}_{2} \cdot 6 \mathrm{H} 2 \mathrm{O}(3.1 \mathrm{~g}, 12.8 \mathrm{mmol})$ in $100 \mathrm{~mL}$ of DMF was refluxed for $6 \mathrm{~h}$. After the mixture was cooled to room temperature, $150 \mathrm{~mL}$ of $\mathrm{H}_{2} \mathrm{O}$ was added. The resultant precipitate was filtered and washed with $50 \mathrm{~mL}$ of $\mathrm{H}_{2} \mathrm{O}$ for two times. The obtained solid was dissolved in $\mathrm{CHCl}_{3}$, followed by washing three times with water. The organic layer was dried over anhydrous magnesium sulfate and evaporated to afford quantitative red crystals.

[5,10,15,20-Tetrakis(4-methoxycarbonylphenyl)porphyrinato]-Ni(II). A solution of TPPCOOMe $0.854 \mathrm{~g}(1.0 \mathrm{mmol})$ and $\mathrm{NiCl}_{2} \cdot 6 \mathrm{H}_{2} \mathrm{O}(3.1 \mathrm{~g}, 12.8 \mathrm{mmol})$ in $100 \mathrm{~mL}$ of DMF was refluxed for $6 \mathrm{~h}$. After the mixture was cooled to room temperature, $150 \mathrm{~mL}$ of $\mathrm{H}_{2} \mathrm{O}$ was added. The resultant precipitate was filtered and washed with $50 \mathrm{~mL}$ of $\mathrm{H}_{2} \mathrm{O}$ for two times. The obtained solid was dissolved in $\mathrm{CHCl}_{3}$, followed by washing three times with $1 \mathrm{M} \mathrm{HCl}$ and twice with water. The organic layer was dried over anhydrous magnesium sulfate and evaporated to afford quantitative crimson crystals.

[5,10,15,20-Tetrakis(4-methoxycarbonylphenyl)porphyrinato]-Zn(II). A solution of TPPCOOMe $0.854 \mathrm{~g}(1.0 \mathrm{mmol})$ and $\mathrm{ZnCl}_{2}(1.75 \mathrm{~g}, 12.8 \mathrm{mmol})$ in $100 \mathrm{~mL}$ of DMF was refluxed for $6 \mathrm{~h}$. After the mixture was cooled to room temperature, $150 \mathrm{~mL}$ of $\mathrm{H}_{2} \mathrm{O}$ was added. The resultant precipitate was filtered and washed with $50 \mathrm{~mL}$ of $\mathrm{H}_{2} \mathrm{O}$ for two times. The obtained solid was dissolved in $\mathrm{CHCl}_{3}$, followed by washing three times with water. The organic layer was dried over anhydrous magnesium sulfate and evaporated to afford quantitative violet crystals.

[5,10,15,20-Tetrakis(4-methoxycarbonylphenyl)porphyrinato]-Fe(III) Chloride. A solution of TPPCOOMe $0.854 \mathrm{~g}(1.0 \mathrm{mmol})$ and $\mathrm{FeCl}_{2} \cdot 4 \mathrm{H}_{2} \mathrm{O}(2.5 \mathrm{~g}, 12.8 \mathrm{mmol})$ in $100 \mathrm{~mL}$ of DMF was refluxed for 6 h. After the mixture was cooled to room temperature, $150 \mathrm{~mL}$ of $\mathrm{H}_{2} \mathrm{O}$ was added. The resultant precipitate was filtered and washed with $50 \mathrm{~mL}$ of $\mathrm{H}_{2} \mathrm{O}$ for two times. The obtained solid was dissolved in $\mathrm{CHCl}_{3}$, followed by washing three times with $1 \mathrm{M} \mathrm{HCl}$ and twice with water. The organic layer was dried over anhydrous magnesium sulfate and evaporated to afford quantitative dark brown crystals.

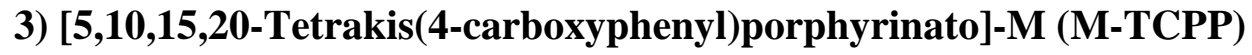

[5,10,15,20-Tetrakis(4-carboxyphenyl)porphyrinato]-Cu(II). The obtained ester $(0.75 \mathrm{~g})$ was stirred in THF (25 mL) and MeOH (25 mL) mixed solvent, to which a solution of $\mathrm{KOH}(2.63 \mathrm{~g}, 46.95 \mathrm{mmol})$ in $\mathrm{H}_{2} \mathrm{O}(25 \mathrm{~mL})$ was introduced. This mixture was refluxed for $12 \mathrm{~h}$. After cooling down to room temperature, THF and $\mathrm{MeOH}$ were evaporated. Additional water was added to the resulting water phase 
and the mixture was heated until the solid was fully dissolved, then the homogeneous solution was acidified with $1 \mathrm{M} \mathrm{HCl}$ until no further precipitate was detected. The dark red was collected by filtration, washed with water and dried in vacuum. FTIR (KBr): v = $3447(\mathrm{~m}), 3060(\mathrm{~m}), 2666(\mathrm{w}), 1696(\mathrm{~s}), 1609$ (m), 1565 (w), 1512 (w), 1456 (m), 1344 (m), 1289 (m), 1175 (m), 1101 (m), 1002 (s), 794 (s), $716(\mathrm{~m})$ $\mathrm{cm}^{-1}$.

[5,10,15,20-Tetrakis(4-carboxyphenyl)porphyrinato]-Co(II). The obtained ester (0.75 g) was stirred in THF (25 mL) and MeOH (25 mL) mixed solvent, to which a solution of $\mathrm{KOH}(2.63 \mathrm{~g}, 46.95 \mathrm{mmol})$ in $\mathrm{H}_{2} \mathrm{O}(25 \mathrm{~mL})$ was introduced. This mixture was refluxed for $12 \mathrm{~h}$. After cooling down to room temperature, THF and $\mathrm{MeOH}$ were evaporated. Additional water was added to the resulting water phase and the mixture was heated until the solid was fully dissolved, then the homogeneous solution was acidified with $1 \mathrm{M} \mathrm{HCl}$ until no further precipitate was detected. The red solid was collected by filtration, washed with water and dried in vacuum. FTIR (KBr): v = $3423(\mathrm{~m}), 2950(\mathrm{w}), 2840(\mathrm{w}), 1719(\mathrm{~s}), 1605$ (s), 1546(m), 1458 (m), 1394 (s), 1351 (m), 1276 (s), 1177 (w), 1112 (s), 1002 (s), 868 (w), 833 (m), 798 (s), $716(\mathrm{~m}) \mathrm{cm}^{-1}$.

[5,10,15,20-Tetrakis(4-carboxyphenyl)porphyrinato]-Ni(II). The obtained ester (0.75 g) was stirred in THF (25 mL) and MeOH (25 mL) mixed solvent, to which a solution of $\mathrm{KOH}(2.63 \mathrm{~g}, 46.95 \mathrm{mmol})$ in $\mathrm{H}_{2} \mathrm{O}(25 \mathrm{~mL})$ was introduced. This mixture was refluxed for $12 \mathrm{~h}$. After cooling down to room temperature, THF and $\mathrm{MeOH}$ were evaporated. Additional water was added to the resulting water phase and the mixture was heated until the solid was fully dissolved, then the homogeneous solution was acidified with $1 \mathrm{M} \mathrm{HCl}$ until no further precipitate was detected. The crimson solid was collected by filtration, washed with water and dried in vacuum. FTIR (KBr): v= $3434(\mathrm{~m}), 3034(\mathrm{~m}), 2790(\mathrm{w}), 1692$ (s), 1609 (s), 1541 (m), 1389(s), 1346 (m), 1311 (m), 1282 (s), 1175 (m), 1106 (m), 1004 (s), 867 (m), $833(\mathrm{~m}), 799(\mathrm{~s}), 716(\mathrm{~m}) \mathrm{cm}^{-1}$.

[5,10,15,20-Tetrakis(4-carboxyphenyl)porphyrinato]-Zn(II). The obtained ester (0.75 g) was stirred in THF (25 mL) and MeOH (25 mL) mixed solvent, to which a solution of $\mathrm{KOH}(2.63 \mathrm{~g}, 46.95 \mathrm{mmol})$ in $\mathrm{H}_{2} \mathrm{O}(25 \mathrm{~mL})$ was introduced. This mixture was refluxed for $12 \mathrm{~h}$. After cooling down to room temperature, THF and $\mathrm{MeOH}$ were evaporated. Additional water was added to the resulting water phase and the mixture was heated until the solid was fully dissolved, then the homogeneous solution was acidified with $1 \mathrm{M} \mathrm{HCl}$ until no further precipitate was detected. The violet solid was collected by filtration, washed with water and dried in vacuum. FTIR (KBr): v = $3438(\mathrm{~m}), 3040(\mathrm{~m}), 2665(\mathrm{w}), 1680$ (s), 1605 (s), 1565 (m), 1504 (m), 1423 (s), 1316 (m), 1291 (s), 1182 (m), 1105 (m), 1002 (s), 867 (m), $798(\mathrm{~s}), 768(\mathrm{~m}), 720(\mathrm{~m}) \mathrm{cm}^{-1}$.

[5,10,15,20-Tetrakis(4-carboxyphenyl)porphyrinato]-Fe(III) Chloride. The obtained ester (0.75 g) was stirred in THF (25 mL) and $\mathrm{MeOH}(25 \mathrm{~mL})$ mixed solvent, to which a solution of $\mathrm{KOH}(2.63 \mathrm{~g}, 46.95$ mmol) in $\mathrm{H}_{2} \mathrm{O}(25 \mathrm{~mL})$ was introduced. This mixture was refluxed for $12 \mathrm{~h}$. After cooling down to room temperature, THF and $\mathrm{MeOH}$ were evaporated. Additional water was added to the resulting water phase and the mixture was heated until the solid was fully dissolved, then the homogeneous solution was acidified with $1 \mathrm{M} \mathrm{HCl}$ until no further precipitate was detected. The brown solid was collected by filtration, washed with water and dried in vacuum. FTIR (KBr): v = $3444(\mathrm{~m}), 3034(\mathrm{w}), 2634(\mathrm{w}), 1702$ (s), 1614 (s), 1570 (m), 1404 (s), 1311 (m), 1277 (s), 1204 (m), 1180 (m), 1106 (m), 1004 (s), 862 (m), $799(\mathrm{~s}), 770(\mathrm{~s}), 721(\mathrm{~m}) \mathrm{cm}^{-1}$. 
Section 3. Synthesis of PCN-226 (M)

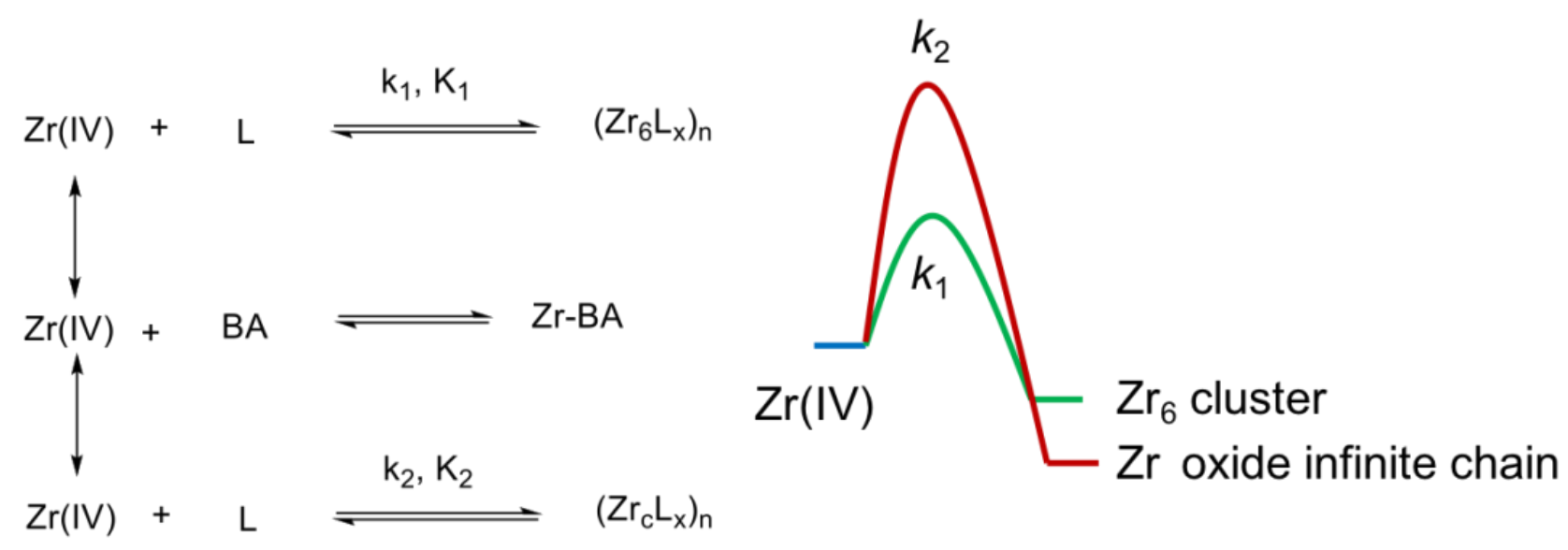

Scheme S2. Synthesis strategy for PCN-226.

Synthesis of PCN-226(Cu). $\mathrm{ZrCl}_{4}(0.21 \mathrm{~g}), \mathrm{CuTCPPCl}(70 \mathrm{mg})$ and benzoic acid $(7.0 \mathrm{~g})$ in $14 \mathrm{~mL}$ of DMF were ultrasonically dissolved in a $20 \mathrm{~mL}$ Pyrex vial. The mixture was heated in $140{ }^{\circ} \mathrm{C}$ oven for 72 h. After cooling down to room temperature, dark red needle shaped crystals were harvested by centrifugation followed by washing by acetone.

Synthesis of PCN-226(Co). $\mathrm{ZrCl}_{4}(0.21 \mathrm{~g})$, CoTCPPCl $(70 \mathrm{mg})$ and benzoic acid $(7.0 \mathrm{~g})$ in $14 \mathrm{~mL}$ of DMF were ultrasonically dissolved in a $20 \mathrm{~mL}$ Pyrex vial. The mixture was heated in $140{ }^{\circ} \mathrm{C}$ oven for 72 h. After cooling down to room temperature, red needle shaped crystals were harvested by centrifugation followed by washing by acetone.

Synthesis of PCN-226(Ni). $\mathrm{ZrCl}_{4}(0.21 \mathrm{~g})$, NiTCPPCl $(70 \mathrm{mg})$ and benzoic acid $(7.0 \mathrm{~g})$ in $14 \mathrm{~mL}$ of DMF were ultrasonically dissolved in a $20 \mathrm{~mL}$ Pyrex vial. The mixture was heated in $140{ }^{\circ} \mathrm{C}$ oven for $72 \mathrm{~h}$. After cooling down to room temperature, crimson needle shaped crystals were harvested by centrifugation followed by washing by acetone.

Synthesis of PCN-226(Zn). $\mathrm{ZrCl}_{4}(0.21 \mathrm{~g}), \mathrm{ZnTCPPCl}(70 \mathrm{mg})$ and benzoic acid $(7.0 \mathrm{~g})$ in $14 \mathrm{~mL}$ of DMF were ultrasonically dissolved in a $20 \mathrm{~mL}$ Pyrex vial. The mixture was heated in $140{ }^{\circ} \mathrm{C}$ oven for 72 h. After cooling down to room temperature, violet needle shaped crystals were harvested by centrifugation followed by washing by acetone.

Synthesis of PCN-226(Fe). $\mathrm{ZrCl}_{4}(0.21 \mathrm{~g})$, FeTCPPCl $(70 \mathrm{mg})$ and benzoic acid $(7.0 \mathrm{~g})$ in $14 \mathrm{~mL}$ of DMF were ultrasonically dissolved in a $20 \mathrm{~mL}$ Pyrex vial. The mixture was heated in $140{ }^{\circ} \mathrm{C}$ oven for $72 \mathrm{~h}$. After cooling down to room temperature, brown needle shaped crystals were harvested by centrifugation followed by washing by acetone.

Synthesis of PCN-222( $\mathbf{H}_{2} / \mathbf{N o}$ metal). $\mathrm{ZrCl}_{4}(0.21 \mathrm{~g}), \mathrm{H}_{2} \mathrm{TCPPCl}(70 \mathrm{mg})$ and benzoic acid $(7.0 \mathrm{~g})$ in 14 $\mathrm{mL}$ of DMF were ultrasonically dissolved in a $20 \mathrm{~mL}$ Pyrex vial. The mixture was heated in $140{ }^{\circ} \mathrm{C}$ oven for $72 \mathrm{~h}$. After cooling down to room temperature, purple needle shaped crystals were harvested by centrifugation followed by washing by acetone. 


\section{Section 4. Structure characterization of PCN-226 $(\mathrm{Cu})$}

The morphology of PCN-226 crystals was observed by scanning electron microscopy (SEM), which shows that the material consists of plank-like crystals with ca. 1-10 $\mu \mathrm{m}$ in length and ca. $500 \mathrm{~nm}$ in thickness (Figure S2). Because the crystal size of PCN-226 is too small for single crystal X-ray diffraction, TEM analysis by using continuous rotation electron diffraction (cRED) method was applied to determine the structure of PCN-226. In total, 432 ED frames with a rotation step of $0.245^{\circ} / \mathrm{frame}$ and an exposure time of $0.5 \mathrm{~s} /$ frame were collected, which covered a tilt range from $60.5^{\circ}$ to $-47.6^{\circ}\left(108.1^{\circ}\right.$ in total, Table S1, Figure S2) for PCN-226(Cu). The unit cell parameters and space group were determined from the cRED data, followed by the refinement of unit cell parameters against powder X-ray diffraction (PXRD) data $(\lambda=1.5406 \AA$ ) using Pawley method (Figure 1). The final unit cell parameters of $a=37.319(4) \AA, b$ $=11.628(11) \AA, c=33.058(3) \AA$, and space group Ibam (No. 72) were used for the structure solution and refinement. Due to the fast data collection $(<3 \mathrm{~min})$, beam damage was minimized. Therefore, we obtained sufficient cRED data of PCN-226 for direct structure solution. The intensities of the reflections were extracted from the cRED data using the X-ray Detector Software $(X D S)^{3}$ (Table S3), and the structure was solved by direct methods using the SHELXT program ${ }^{5}$. All non-hydrogen atoms $(\mathrm{Zr}, \mathrm{Cu}$, $\mathrm{C}, \mathrm{O}$, and $\mathrm{N}$ ) except three $\mathrm{C}$ atoms in the benzyl group of BA molecule were found directly. The remaining three $\mathrm{C}$ atoms in the benzyl group of BA were completed from the difference electrostatic potential map (Figure S3).

The SHELXL package ${ }^{4,5}$ was used for structure refinement. Considering the electron source, the atomic scattering factor for electrons was implemented based on neutral carbon, nitrogen and oxygen atoms and charged copper and zirconium cations. All atoms were refined isotropically. EADP were applied on the carbon, nitrogen, oxygen and zirconium atoms. The carbon atoms (C1-C7) in the benzyl group were treated as a rigid body. A planarity restraint (FLAT) was applied to the benzyl groups and the phenyl groups to maintain a reasonable geometry. Next, the anti-bumping restrains were used to keep the reasonable distances between different benzyl groups and between oxygen atoms in the framework and water molecules. We also restrained the distance of the copper atom to keep it in the center of the porphyrin. The similarity restraints as a combination of the free variables and the DFIX with DANG instruction were used. In the case there was no sufficient number of variables to perform the similarity restraints, the DFIX and DANG instructions were applied separately. In this way we could preserve the reasonable geometry for PCN-226. At the end, SWAT was used in the refinement. Finally, the refinement was converged with the agreement values $R_{1}=25.05 \%$ for $1485 \mathrm{~F}_{\mathrm{o}}>4 \sigma\left(\mathrm{F}_{\mathrm{o}}\right)$ and $27.29 \%$ for all 1842 data (Table S4).

HRTEM images were obtained to confirm the structure. Because MOFs are highly sensitive to electron beam, we minimized the acquisition time and electron dose to reduce beam damage. A through-focus series of 25 HRTEM images with a constant defocus step of $53.3 \AA$ was used. A structure projection along the $b$-axis was reconstructed using the program $Q F o c u s^{6}$. The HRTEM images show a good agreement with the refined structure (Figures $1 \mathrm{c}$ and $\mathrm{d}$ ).

The obtained model shows the $\mathrm{Zr}(\mathrm{IV})$ cations in PCN-226 are hepta-coordinated with capped octahedral geometry. Each $\mathrm{Zr}(\mathrm{IV})$ cation coordinates to four oxygen atoms from four carboxylates and three $\mu_{3}-$ oxygen atoms to form an edge-sharing infinite zigzag $\mathrm{ZrO}_{7}$ chain, which runs along the $b$-axis. The chains are linked with metalloporphyrin molecules to form a 3D framework. The channels of PCN-226 contains a straight pore $(7.2 \AA \times 4.8 \AA)$ formed by in-plane arrangement of porphyrins, and a peristaltic shape pore 
$(5.4 \AA \times 4.2 \AA$ ) formed by an alternatively crossed arrangement of the porphyrins. Both elliptical pores are interconnected to form a 2D channel system (Figures 2c, 2d, and S6). HRTEM images (Figures 1c and d) clearly show the rectangular pore arrangement along the [010] direction with $d_{200}=18.32 \AA$ and $d_{002}=16.18 \AA$, which is in good agreement with the structural model (calculated $d_{200}=18.53 \AA$ and $d_{002}$ $=16.25 \AA) . \mathrm{N}_{2}$ sorption measurements show a typical type I isotherm of PCN-226(Cu) with a steep increase at $P / P_{0}=0.08$, which suggests the microporosity. A $\mathrm{N}_{2}$ uptake of $10.1 \mathrm{mmol} / \mathrm{g}$ and a BrunauerEmmett-Teller (BET) surface area of $800 \mathrm{~m}^{2} \mathrm{~g}^{-1}$ were calculated for PCN-226(Cu) (Figure S7). Moreover, the experimental total pore volume of $0.32 \mathrm{~cm}^{3} \mathrm{~g}^{-1}$ is also in good agreement with the calculated pore volume of $0.25 \mathrm{~cm}^{3} \mathrm{~g}^{-1}$. The theoretical surface area of PCN-226 was calculated on the basis of the purposed structural model. The van der Waals radii of $\mathrm{C}, \mathrm{H}, \mathrm{O}, \mathrm{N}, \mathrm{Zr}, \mathrm{Cu}$ were applied to generate the $\mathrm{vdW}$ surface of PCN-226. The theoretical value was further calculated from the surface, which is generated by tracing the center of the probe molecule (liquid $\mathrm{N}_{2}$, kinetic radius $=1.82 \AA$ ) as it rolls along the vdW surface of PCN-226.

\section{Section 5. Electrochemical analysis of PCN-226 (Co)}

\subsection{ORR}

\subsubsection{Electrochemical ORR measurement}

All the electrochemical ORR measurements were performed at $\sim 25^{\circ} \mathrm{C}$ with a $\mathrm{CH}$ Instruments (CHI $760 \mathrm{E}$ Electrochemical Analyzer) and a Pine Modulated Speed Rotator (Pine Research Instrumentation, Inc.). For the measurement of the ORR, cyclic voltammetry (CV) measurements were carried out in $\mathrm{N}_{2} / \mathrm{O}_{2}-$ saturated $0.1 \mathrm{M} \mathrm{KOH}$ solution at $\sim 25^{\circ} \mathrm{C}$ with a scan rate of $50 \mathrm{mV} \mathrm{s}^{-1}$. We selected the rotating ringdisk electrode (RRDE) as the working electrode, carbon rod as the auxiliary electrode, and saturated $\mathrm{Ag} / \mathrm{AgCl}$ as the reference electrode. Specifically, the area of the disk is $0.247 \mathrm{~cm}^{2}$ and the area of the ring is $0.186 \mathrm{~cm}^{2}$. In order to evaluate the catalytic activity of PCN-226s (M, M= Fe, Co, Ni, Cu, Zn), $1 \mathrm{mg}$ of catalysts and $4 \mu \mathrm{L}$ of Nafion solution (5 wt \%, DuPont) were added into $246 \mu \mathrm{L}$ of water/isopropanol solution $\left(V_{\text {water }}: V_{\text {isopropanol }}=3: 1\right)$ and then ultrasonicated for $\sim 1 \mathrm{~h}$ to prepare a homogeneous slurry. Then, $20 \mu \mathrm{L}$ of the catalysts was coated onto the RRDE electrode using pipette and dried naturally. In addition, carbon black was introduced to improve the conductivity. In a typical procedure, $1 \mathrm{mg}$ of catalysts and $1 \mathrm{mg}$ of carbon black were added into $16 \mu \mathrm{L}$ of Nafion solution (5 wt\%, DuPont) and 984 $\mu \mathrm{L}$ of water/isopropanol solution ( $V_{\text {water }}: V_{\text {isopropanol }}=3: 1$ ). Finally, $20 \mu \mathrm{L}$ of the mixed catalysts was coated onto the RRDE electrode to form a homogeneous membrane. The catalyst loading of PCN-226 on the RRDE electrode is $0.08 \mathrm{mg} \mathrm{cm}^{-2}$. The linear sweep voltammetry (LSV) was measured in $\mathrm{O}_{2}$-saturated $0.1 \mathrm{M} \mathrm{KOH}$ solution at a scan rate of $10 \mathrm{mV} \mathrm{s}^{-1}$ and an electrode rotation speed of $1600 \mathrm{rpm}$. The durability test was carried out at 0.46 (V vs RHE) and $1600 \mathrm{rpm}$ in $\mathrm{O}_{2}$-saturated $0.1 \mathrm{M} \mathrm{KOH}$ solution.

The Tafel slope of PCN-226(Co), PCN-221(Co), PCN-222(Co), and Pt/C was calculated as 58.9, 77.6, 72.0 , and $75.5 \mathrm{mV} \mathrm{dec}^{-1}$, respectively, at low current densities, and 1352, 1413,1539, and $4260 \mathrm{mV} \mathrm{dec}^{-1}$, respectively, at high current densities. This shows PCN-226 has the fastest reaction kinetics among them (Figure 3d). Moreover, PCN-226(Co) exhibits a superior tolerance to methanol crossover, which is crucial for applications in alkaline direct methanol fuel cells. The current density of PCN-226(Co) remained constant after the injection of methanol (5 v\%), while a significant decrease in current was observed for the Pt/C catalyst (Figure S28). 


\subsubsection{Calculation of electron transfer number $(n)$}

Electrocatalytic ORR can be carried out in alkaline solution through four electron $\left(4 \mathrm{e}^{-}\right)$pathway,

$\mathrm{O}_{2}+2 \mathrm{H}_{2} \mathrm{O}+4 \mathrm{e}^{-} \rightarrow 4 \mathrm{OH}^{-}$

and two electron $\left(2 \mathrm{e}^{-}\right)$pathway.

$\mathrm{O}_{2}+\mathrm{H}_{2} \mathrm{O}+2 \mathrm{e}^{-} \rightarrow \mathrm{HO}_{2}^{-}+\mathrm{OH}^{-}$

$\mathrm{HO}_{2}{ }^{-}+\mathrm{H}_{2} \mathrm{O}+2 \mathrm{e}^{-} \rightarrow 3 \mathrm{OH}^{-}$

The corresponding electron transfer number $(n)$ of PCN-226(Co) was calculated as following,

$$
n=4 \frac{i_{\mathrm{d}}}{i_{\mathrm{d}}+i_{\mathrm{r}} / N}
$$

where $i_{\mathrm{d}}$ and $i_{\mathrm{r}}$ are the disk and ring current of RRDE, respectively, and the number can be obtained from LSV measurements. $N$ is the ring current collection efficiency (0.37).

For example, the values of $i_{\mathrm{d}}$ and $i_{\mathrm{r}}$ of PCN-226(Co) at $0.55 \mathrm{~V}$ (vs RHE) are 0.000657 and $0.0000467 \mathrm{~A}$, respectively. Therefore, $n$ was calculated as,

$$
4 \times \frac{0.000657}{0.000657+0.000467 / 0.37}=3.35 \text {. }
$$

The disk current density $j_{\mathrm{d}}$ and the ring current density $j_{\mathrm{r}}$, such as shown in Figure $3 \mathrm{~b}$, were calculated as,

$$
j_{\mathrm{d}}=\frac{i_{\mathrm{d}}}{S_{\mathrm{d}}}, j_{\mathrm{r}}=\frac{i_{\mathrm{i}}}{S_{\mathrm{r}}}
$$

where $S_{\mathrm{d}}$ is the surface area of disk for RRDE and $S_{\mathrm{r}}$ is the surface area of ring for RRDE. In our case, the $S_{\mathrm{d}}$ and $S_{\mathrm{r}}$ are 0.247 and $0.186 \mathrm{~cm}^{2}$, respectively. Thus, for example, $j_{\mathrm{d}}$ and $j_{\mathrm{r}}$ of PCN-226(Co) at $0.55 \mathrm{~V}$ (vs RHE) are calculated as $j_{\mathrm{d}}=0.000657 \mathrm{~A} / 0.247 \mathrm{~cm}^{2}=2.66 \mathrm{~mA} \mathrm{~cm}^{-2}$, and $j_{\mathrm{r}}=0.0000467 \mathrm{~A} / 0.186 \mathrm{~cm}^{2}$ $=0.25 \mathrm{~mA} \mathrm{~cm}^{-2}$, as shown in Figure $3 \mathrm{~b}$.

\subsubsection{Calculation of turnover frequency (TOF)}

The turnover frequency (TOF) could be calculated with the $E q$ (5):

$$
\mathrm{TOF}=\frac{J * S}{4 * n * F}
$$

where the $J$ is the current density at a given potential, the $S$ is the surface area of the RRDE $\left(0.247 \mathrm{~cm}^{2}\right)$, the $F$ is the faraday constant $\left(96485.3 \mathrm{~s} \mathrm{~A} \mathrm{~mol}^{-1}\right)$, and the $n$ is the number of the active sites. Herein, the actives sites of PCN-226 are the transitional metal atoms (i.e. Co). Therefore, the $n$ for the Co of PCN226 is $1.1 * 10^{-5} \mathrm{mmol}$ calculated with the following $E q(6)$.

$$
n_{(C o)}=\frac{0.08 \mathrm{mg} / \mathrm{cm}^{2} * 0.247 \mathrm{~cm}^{2} * 3.27 \%}{59 \mathrm{~g} / \mathrm{mol}}=1.1 * 10^{-5} \mathrm{mmol}
$$

In contrast, the $\mathrm{n}$ for the $\mathrm{Pt}$ of $\mathrm{Pt} / \mathrm{C}$ is $2.0^{*} 10^{-5} \mathrm{mmol}$ calculated with the following $E q$ (7).

$$
n_{(P t)}=\frac{0.08 \mathrm{mg} / \mathrm{cm}^{2} * 0.247 \mathrm{~cm}^{2} * 20 \%}{195 \mathrm{~g} / \mathrm{mol}}=2.0 * 10^{-5} \mathrm{mmol}
$$


The $J$ of the $\mathrm{PCN}-226(\mathrm{Co})$ and $\mathrm{Pt} / \mathrm{C}$ is 2.9 and $5.6 \mathrm{~mA} \mathrm{~cm}^{-2}$, respectively.

\subsection{OER}

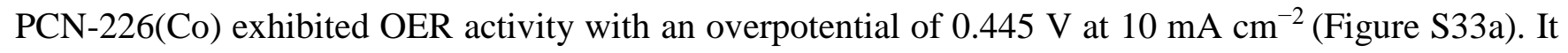
was measured using a $\mathrm{CH}$ Instruments (CHI 660E Electrochemical Analyzer). Typical three electrode system was applied with glassy carbon as working electrode, $\mathrm{Ag} / \mathrm{AgCl}$ as the reference electrode, and carbon rod as the counter electrode. The LSV curve was measured with the scan rate of $10 \mathrm{mV} \mathrm{s}^{-1}$ in 1.0 $\mathrm{M} \mathrm{KOH}$. The overpotential $\eta$ for PCN-226(Co) at $10 \mathrm{~mA} \mathrm{~cm} \mathrm{~cm}^{-2}$ can be calculated with the following Eq (8).

$$
\eta_{10}=\left(E_{\mathrm{Ag} / \mathrm{AgCl}}+0.197+0.059 * p H-1.23\right) \mathrm{V}
$$

The Tafel slope of PCN-226(Co) for OER was calculated as $111 \mathrm{mV} \mathrm{dec}^{-1}$ (Figure S33b), which was obtained by measuring LSV curve at a scan rate of $2 \mathrm{mV} \mathrm{s}^{-1}$. We anticipate the bifunctionality is important for practical applications.

\section{$5.3 \mathrm{Zn}$-air battery}

A typical rechargeable $\mathrm{Zn}$-air battery in this study consists three parts: the anode (Zn plate), electrolyte (6.0 M KOH + 0.20 $\left.\mathrm{M} \mathrm{ZnCl}_{2}\right)$, and cathode (PCN-226(Co)/C). In particular, the cathode was prepared by coating the catalyst $\left(0.50 \mathrm{mg} \mathrm{cm}{ }^{-2}\right)$ on the carbon cloth/gas diffusion layer hybrid electrode. The electrochemical test was carried out with an electrochemical workstation (CHI 660E). The long-term cycling performance of $\mathrm{Zn}$-air battery assembled with $\mathrm{PCN}-226(\mathrm{Co})$ and $\mathrm{Pt} / \mathrm{C}+\mathrm{RuO}$, respectively, was tested at $j=2 \mathrm{~mA} \mathrm{~cm}^{-2}$. PCN-226(Co) displayed a discharge/charge durability for at least $160 \mathrm{~h}$, while the battery assembled with $\mathrm{Pt} / \mathrm{C}+\mathrm{RuO}_{2}$ lost activity after $50 \mathrm{~h}$ (Figure $4 \mathrm{e}$ ). This indicates a better electrocatalytic durability of PCN-226(Co).

\section{Section 6. Theoretical calculation}

We performed density functional theory (DFT) calculations using VASP ${ }^{7,8}$ code and BEEF-vdw ${ }^{9}$ exchange-correlation functional. Projector augmented wave $(\mathrm{PAW})^{10}$ pseudopotential was used to describe an interaction between core and valence electrons. An energy cutoff and convergence criteria for self-consistent iteration and geometry optimization were set to $500 \mathrm{eV}, 10^{-4} \mathrm{eV}$ and $0.05 \mathrm{eV} \AA^{-1}$, respectively. Gamma point was used to sample the reciprocal space of non-periodic system.

The calculated electronic energies were converted into the free energies by including adsorbate free energy correction terms calculated from harmonic oscillator approximation as implemented in Atomic Simulation Environment ${ }^{11} ; 0.03 \mathrm{eV}$ for $\mathrm{O}^{*}, 0.29 \mathrm{eV}$ for $\mathrm{OH}^{*}, 0.35 \mathrm{eV}$ for $\mathrm{OOH}^{*}$. The molecular energies of $\mathrm{H}_{2}$ and $\mathrm{H}_{2} \mathrm{O}$ were calculated in $10 \times 10 \times 10 \AA^{3}$ box, and free energy corrections were added based on the ideal gas approximation. The computational hydrogen electrode method ${ }^{12}$ was used to consider the effect of an electrode potential, and we used potential dependent free energies to construct a free energy diagram. We note that a solvation stabilization was not included since it has been reported to be negligible for an isolated metal site. ${ }^{13}$ 


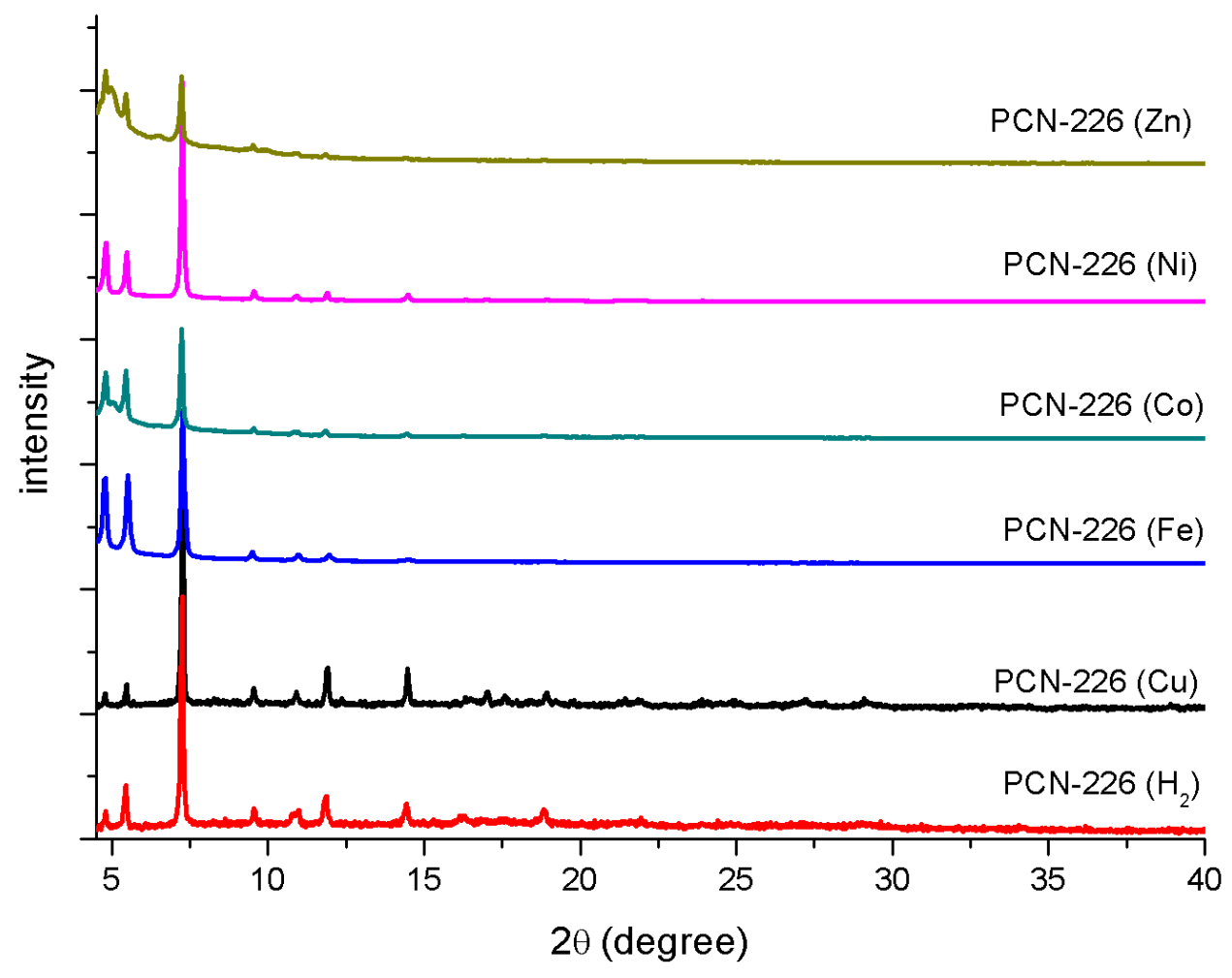

Figure S1. PXRD patterns of PCN-226(M, M=Zn, Ni, Co, Fe, Cu, $\left.\mathrm{H}_{2}\right)$, showing a series of isostructures of PCN226.
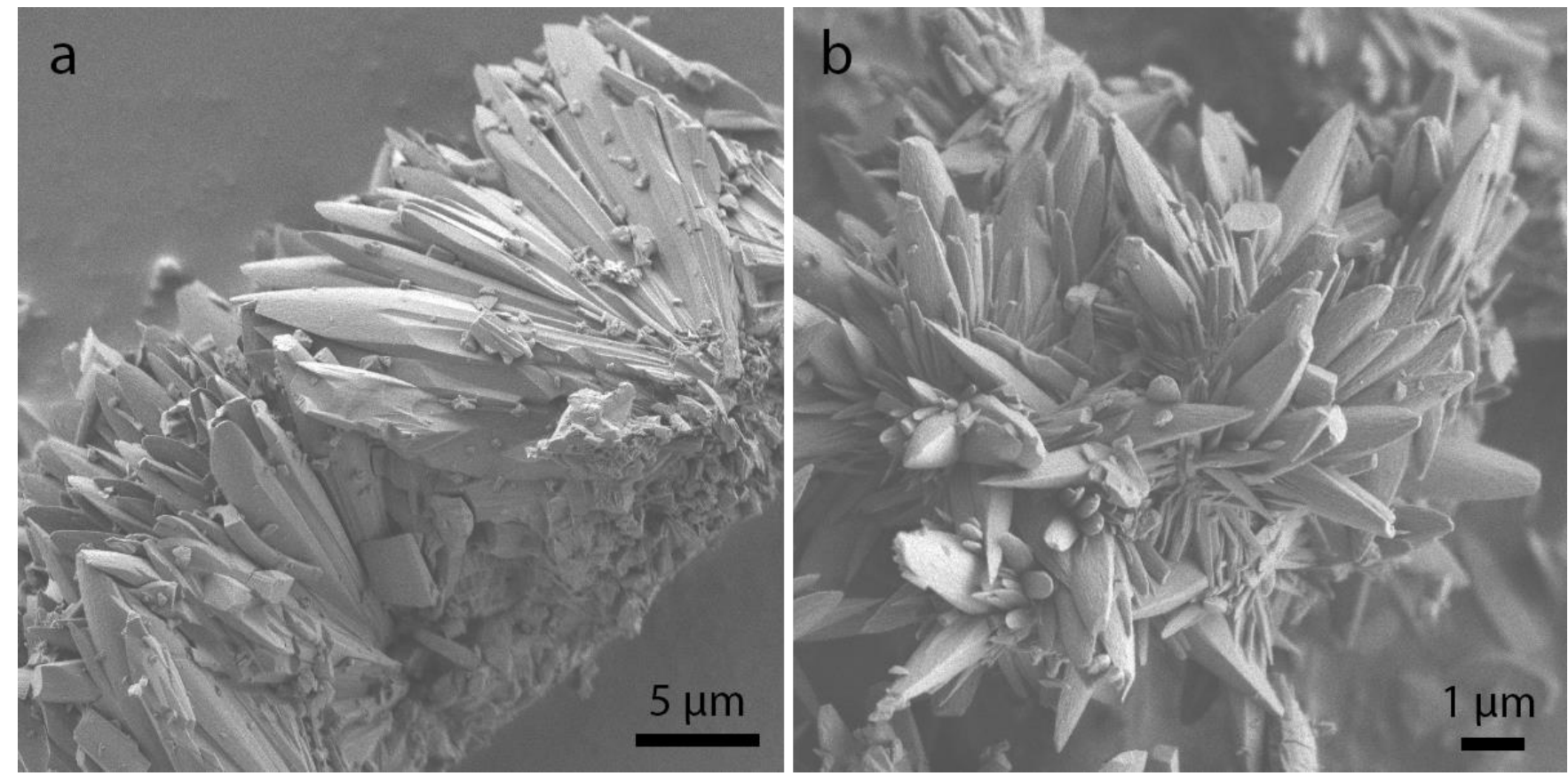

Figure S2. SEM images of PCN-226(Cu) (a) and PCN-226(Co) (b), showing a long and plank-like crystal morphology. 


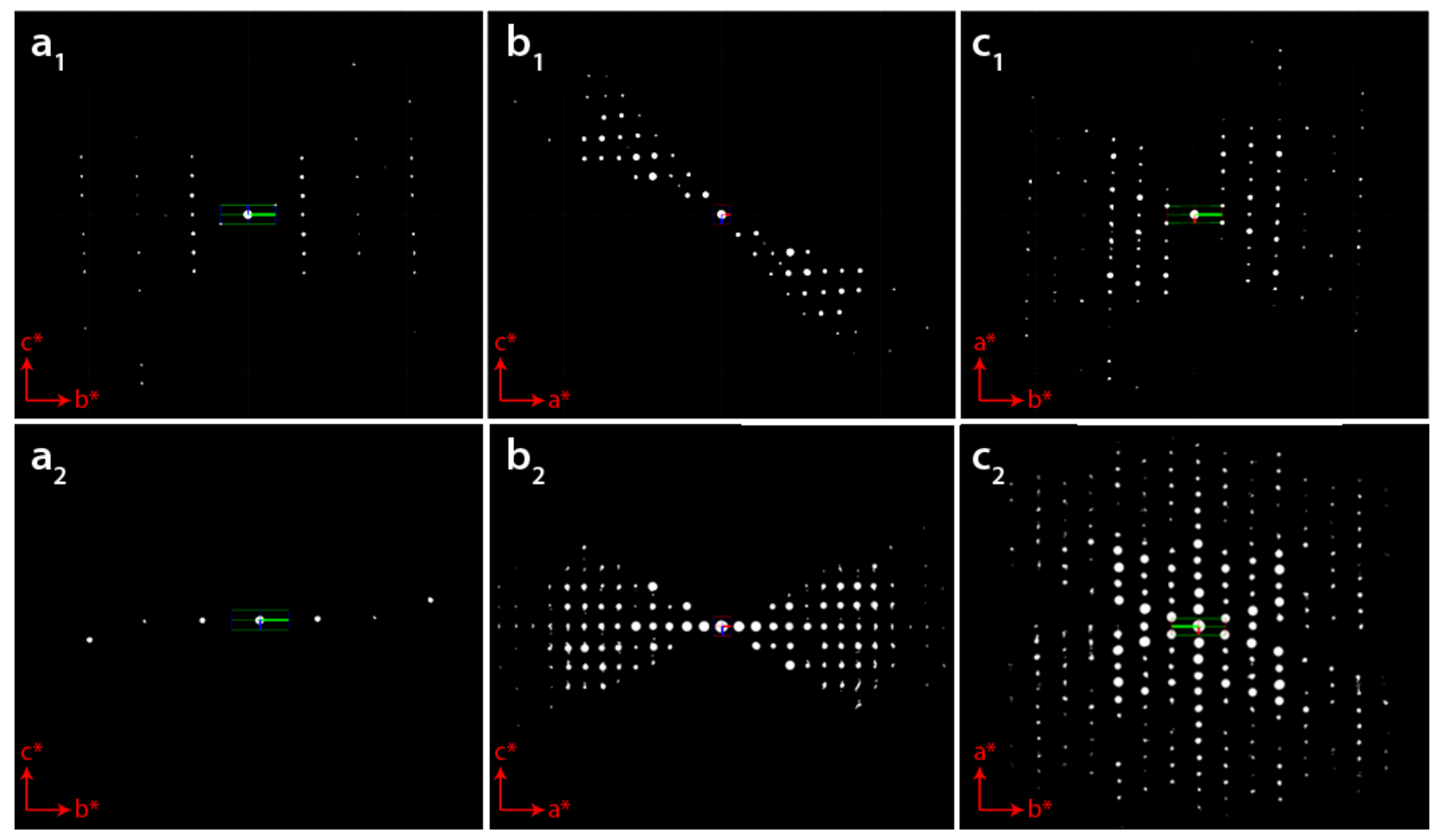

Figure S3. 2D slice cuts from the 3D reciprocal lattice of PCN-226(Cu) and PCN-226(Co) reconstructed from the cRED data by using RED $p$ software ${ }^{14}$. $\left(\mathrm{a}_{1}\right.$ and $\left.\mathrm{a}_{2}\right) 0 k l$, $\left(\mathrm{b}_{1}\right.$ and $\left.\mathrm{b}_{2}\right) h 0 l$ and $\left(\mathrm{c}_{1}\right.$ and $\left.\mathrm{c}_{2}\right) h k 0$ reciprocal planes. The reflection conditions can be deduced as, $h k l: h+k+l=2 n ; 0 k l: k, l=2 n ; h 0 l: h, l=2 n ; h k 0: h+k=2 n ; h 00: h=2 n ; 0 k 0$ : $k=2 n ; 00 l: l=2 n$. The similar intensity distribution of PCN-226(Cu) and PCN-226(Co) shows that they have the same structure.

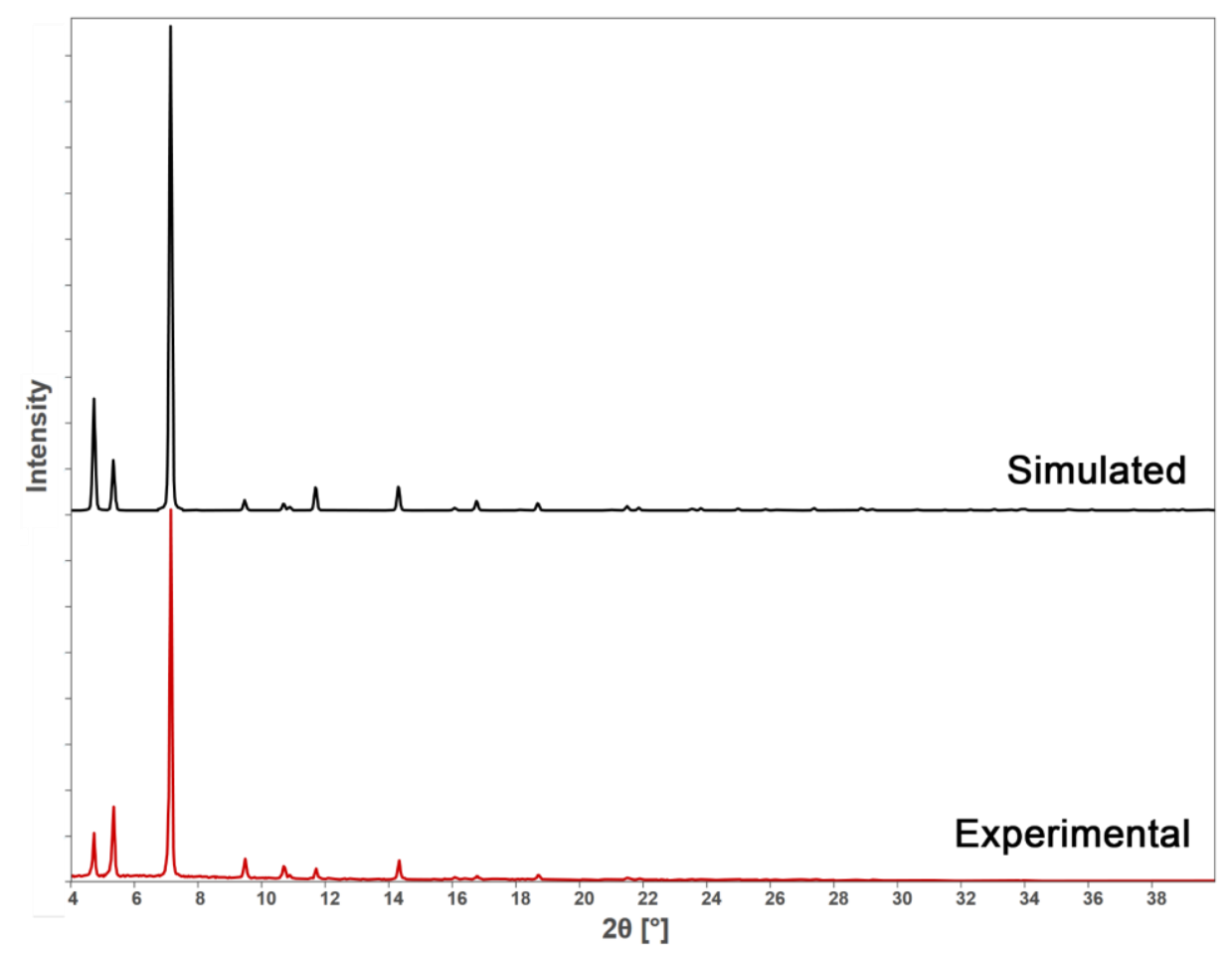

Figure S4. Experimental and simulated PXRD patterns $(\lambda=1.5406 \AA)$ of PCN-226(Cu). The intensity difference in small angle region is caused by the captured guest molecules in the pores. They were not fully identified in the crystallographic structural model due to the disorder and low occupancy. 


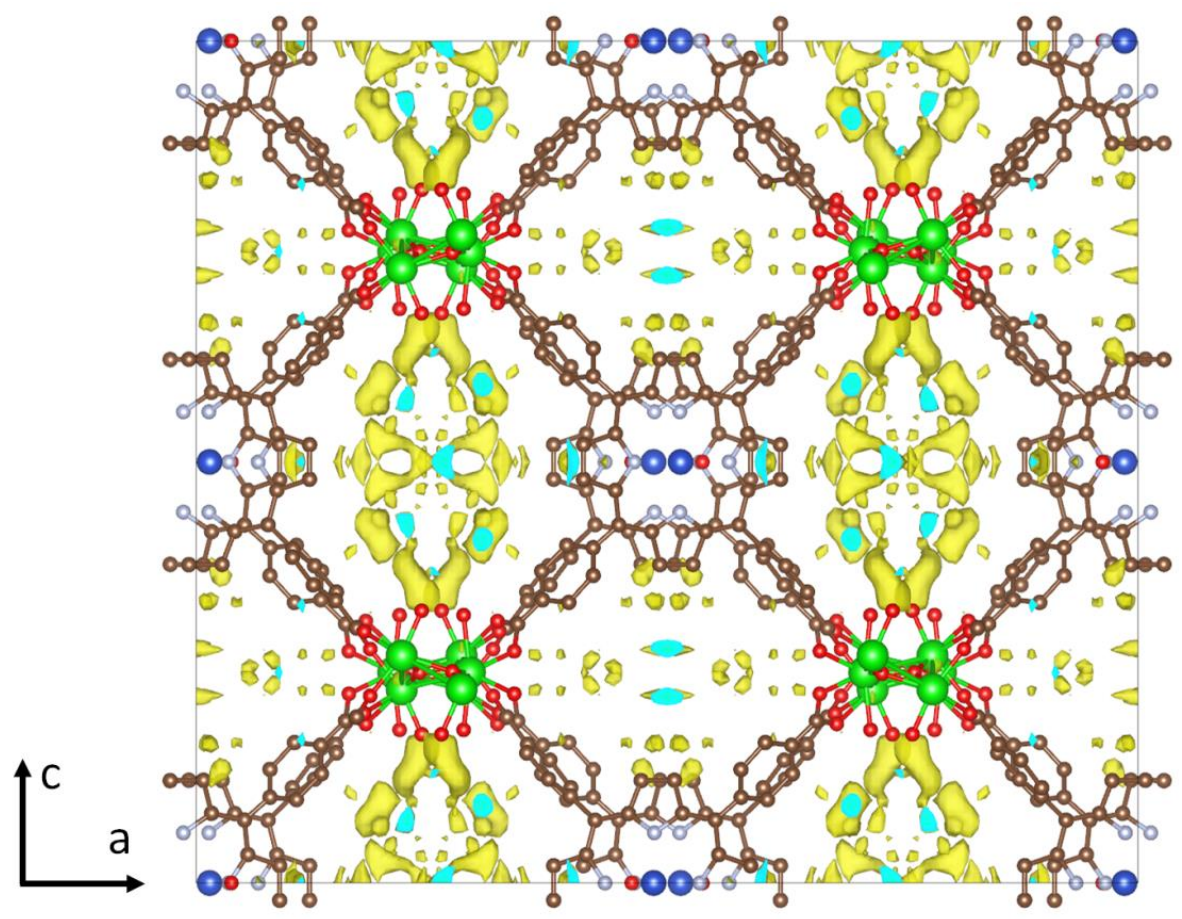

Figure S5. Difference electrostatic potential map of PCN-226(Cu) showing a clear positive residual electron potential from BAs. The map is contoured at $3 \sigma$-level. Green: $\mathrm{Zr}$; blue: $\mathrm{Cu}$; red: O; brown: $\mathrm{C}$; light cyan: N; yellow: electron potential. 


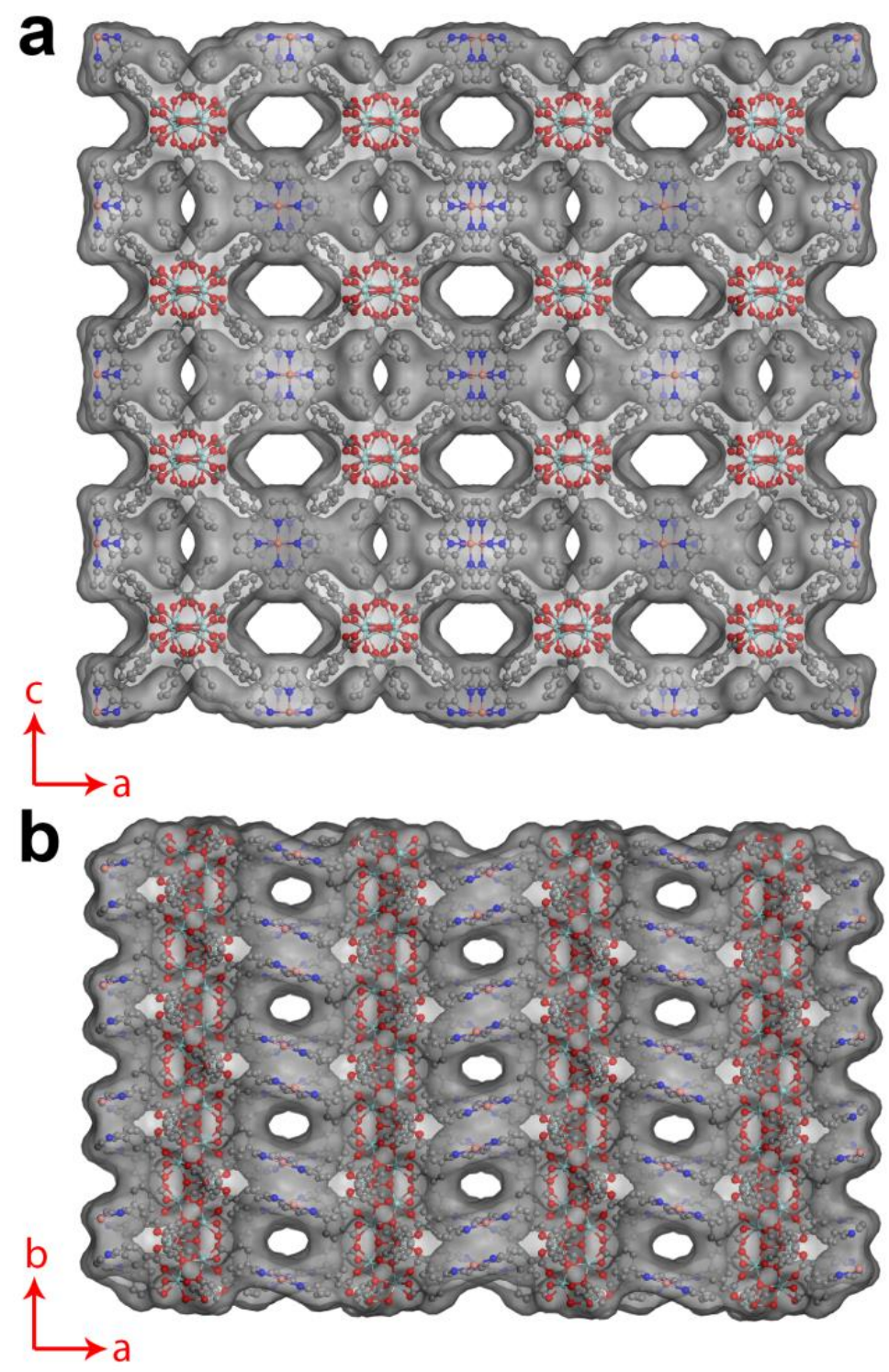

Figure S6. The accessible pores of PCN-226(Cu) viewing along [010] (a) and [001] (b). 

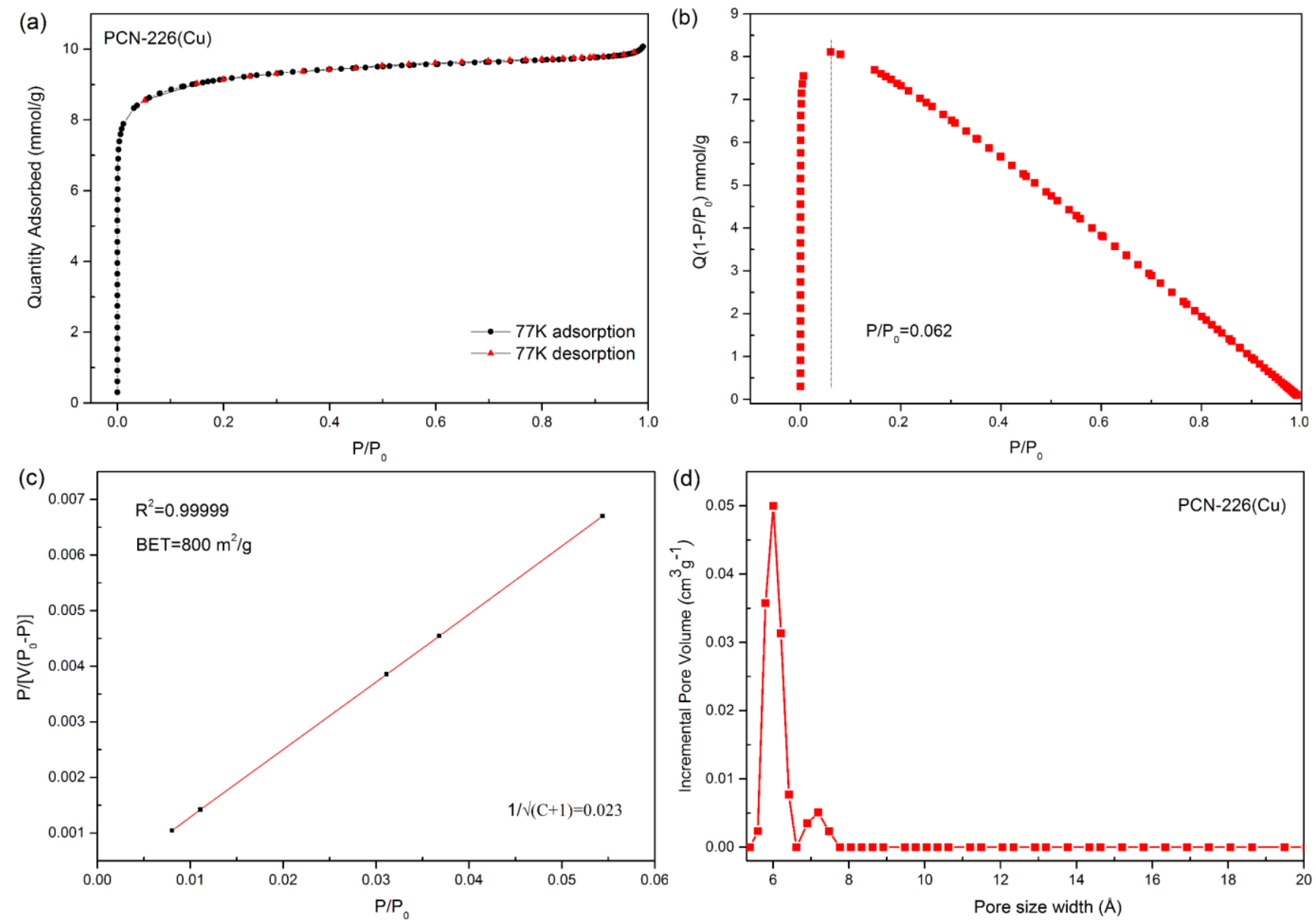

(e)

\begin{tabular}{|l|l|}
\hline $\mathrm{P} / \mathrm{P}_{0}$ Range & $0.0080-0.0544$ \\
\hline Correlation Coefficient & 0.99999 \\
\hline $\mathrm{C}$ & 1875 \\
\hline $\mathrm{Q}_{\mathrm{m}}(\mathrm{mmol} / \mathrm{g})$ & 8.2 \\
\hline $1 \sqrt{ }(C+1)$ & 0.023 \\
\hline BET Surface Area $\left(\mathrm{m}^{2} / \mathrm{g}\right)$ & 800 \\
\hline
\end{tabular}

Figure S7. Porosity analysis of PCN-226(Cu). (a-b) $\mathrm{N}_{2}$ adsorption-desorption isotherms and the analysis of PCN$226(\mathrm{Cu})$ at $77 \mathrm{~K}$. (c) Plot of the linear region of the adsorption $\mathrm{N}_{2}$ isotherm used for the BET equation. (d) Pore size distributions calculated by NLDFT. (e) Summary of parameters in the BET analysis. 

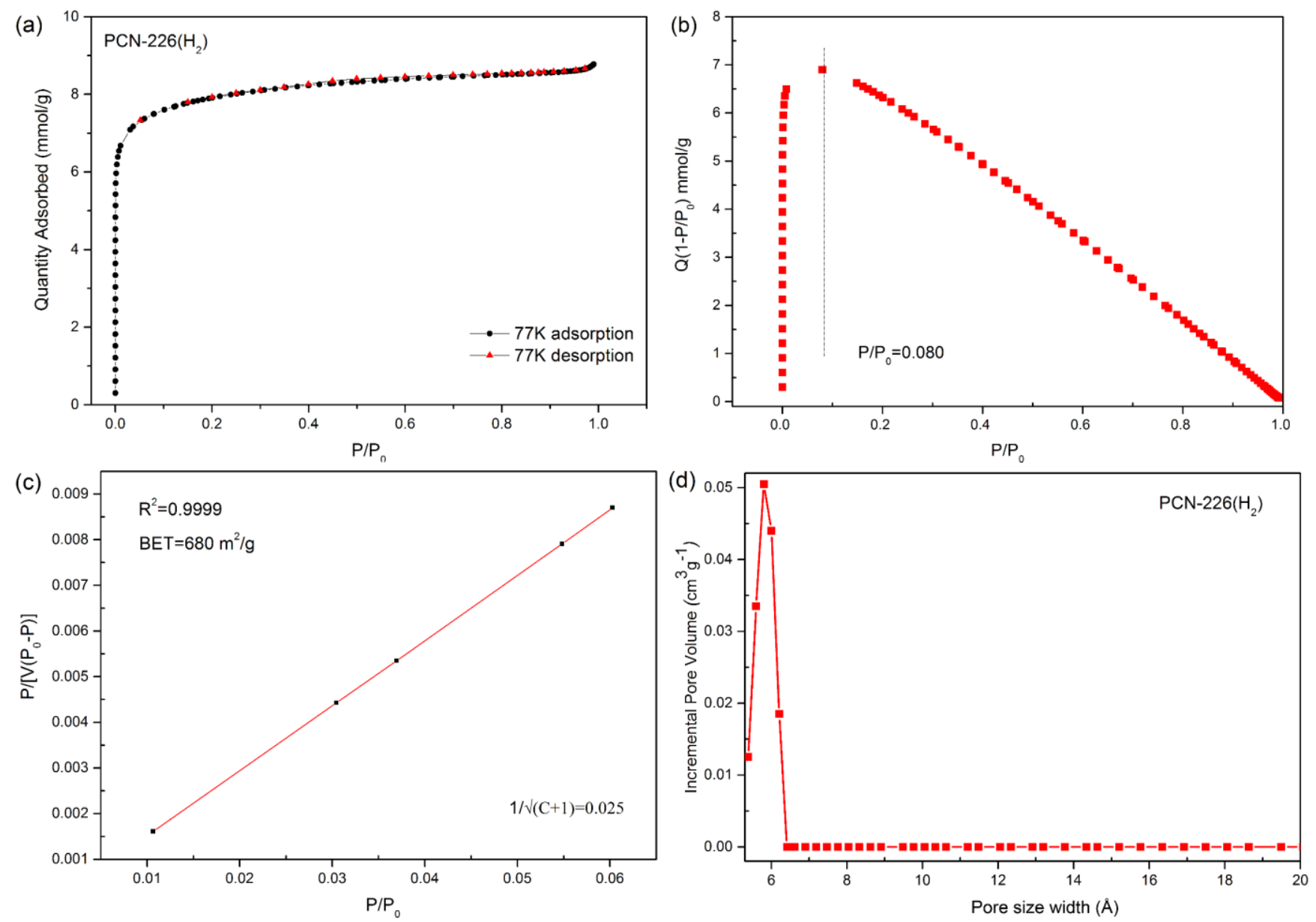

\begin{tabular}{l|l|l|}
\cline { 2 - 3 } (e) & $\mathrm{P} / \mathrm{P}_{0}$ Range & $0.0106-0.0603$ \\
\hline Correlation Coefficient & 0.99999 \\
\hline $\mathrm{C}$ & 1660 \\
\hline $\mathrm{Q}_{\mathrm{m}}(\mathrm{mmol} / \mathrm{g})$ & 7.0 \\
\hline $1 \sqrt{ }(C+1)$ & 0.025 \\
\hline BET Surface Area $\left(\mathrm{m}^{2} / \mathrm{g}\right)$ & 680 \\
\hline
\end{tabular}

Figure S8. Porosity analysis of PCN-226( $\left.\mathrm{H}_{2}\right)$. (a-b) $\mathrm{N}_{2}$ adsorption-desorption isotherms and the analysis of PCN$226\left(\mathrm{H}_{2}\right)$ at $77 \mathrm{~K}$. (c) Plot of the linear region of the adsorption $\mathrm{N}_{2}$ isotherm used for the BET equation. (d) Pore size distributions calculated by NLDFT. (e) Summary of parameters in the BET analysis. 

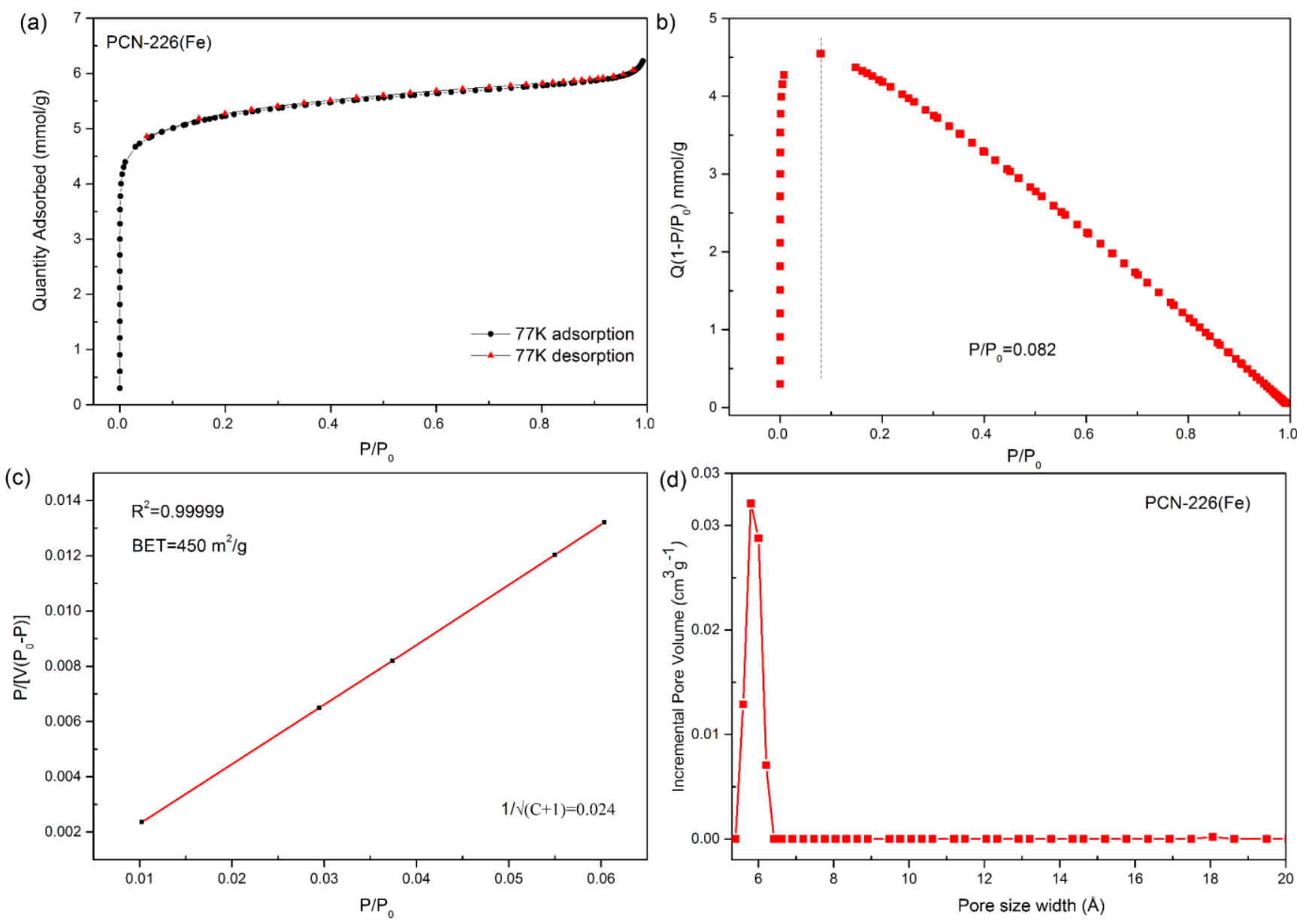

(e)

\begin{tabular}{|l|l|}
\hline $\mathrm{P} / \mathrm{P}_{0}$ Range & $0.0102-0.0603$ \\
\hline Correlation Coefficient & 0.99999 \\
\hline $\mathrm{C}$ & 2187 \\
\hline $\mathrm{Q}_{\mathrm{m}}(\mathrm{mmol} / \mathrm{g})$ & 4.60 \\
\hline $1 \sqrt{ }(C+1)$ & 0.024 \\
\hline BET Surface Area $\left(\mathrm{m}^{2} / \mathrm{g}\right)$ & 449 \\
\hline
\end{tabular}

Figure S9. Porosity analysis of PCN-226(Fe). (a-b) $\mathrm{N}_{2}$ adsorption-desorption isotherms and the analysis of PCN$226(\mathrm{Fe})$ at $77 \mathrm{~K}$. (c) Plot of the linear region of the adsorption $\mathrm{N}_{2}$ isotherm used for the BET equation. (d) Pore size distributions calculated by NLDFT. (e) Summary of parameters in the BET analysis. 

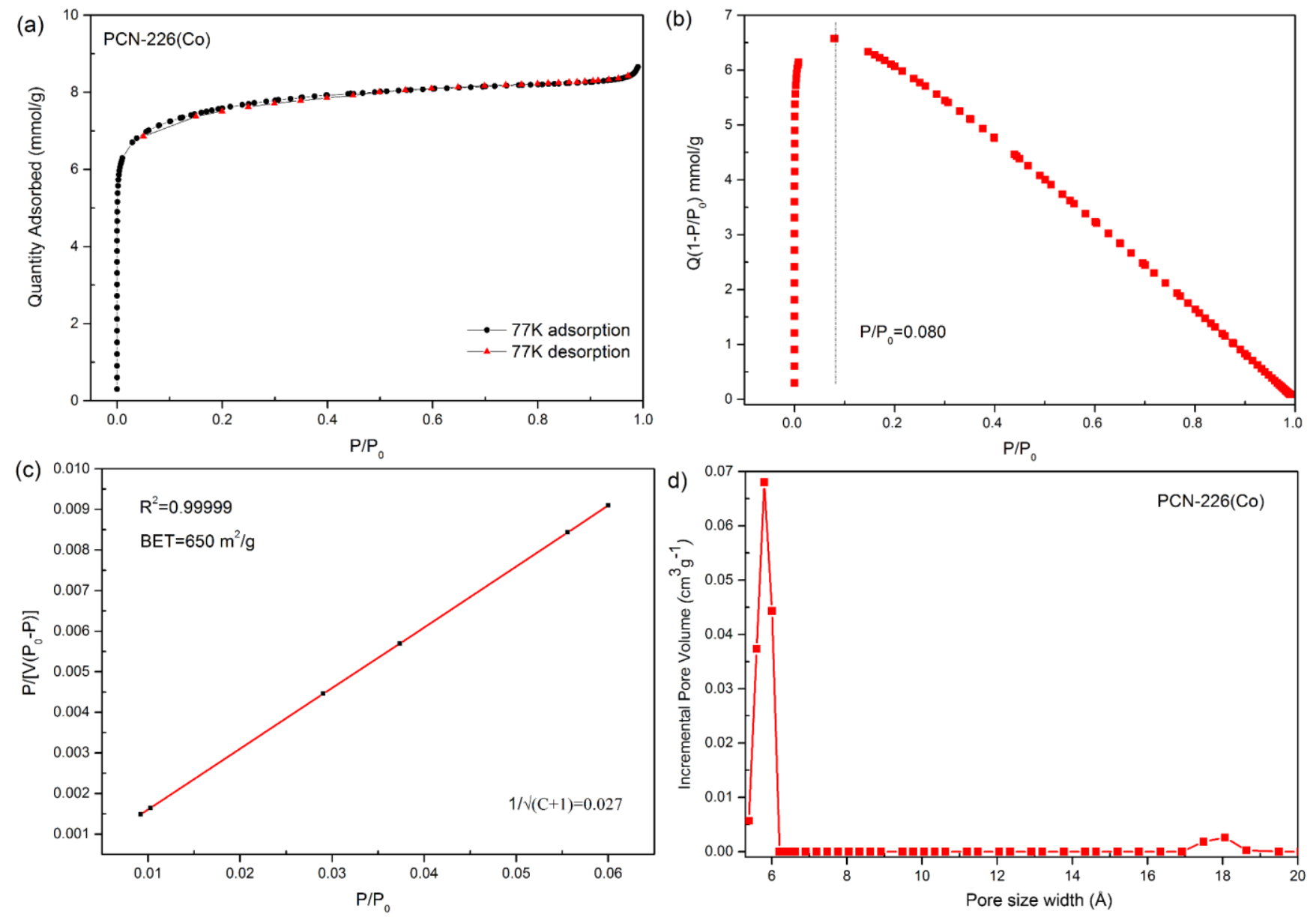

(e)

\begin{tabular}{|l|l|}
\hline $\mathrm{P} / \mathrm{P}_{0}$ Range & $0.0092-0.0600$ \\
\hline Correlation Coefficient & 0.99999 \\
\hline $\mathrm{C}$ & 1387 \\
\hline $\mathrm{Q}_{\mathrm{m}}(\mathrm{mmol} / \mathrm{g})$ & 6.7 \\
\hline $1 \sqrt{ }(C+1)$ & 0.027 \\
\hline BET Surface Area $\left(\mathrm{m}^{2} / \mathrm{g}\right)$ & 650 \\
\hline
\end{tabular}

Figure S10. Porosity analysis of PCN-226(Co). (a-b) $\mathrm{N}_{2}$ adsorption-desorption isotherms and the analysis of PCN$226(\mathrm{Co})$ at $77 \mathrm{~K}$. (c) Plot of the linear region of the adsorption $\mathrm{N}_{2}$ isotherm used for the BET equation. (d) Pore size distributions calculated by NLDFT. (e) Summary of parameters in the BET analysis. 

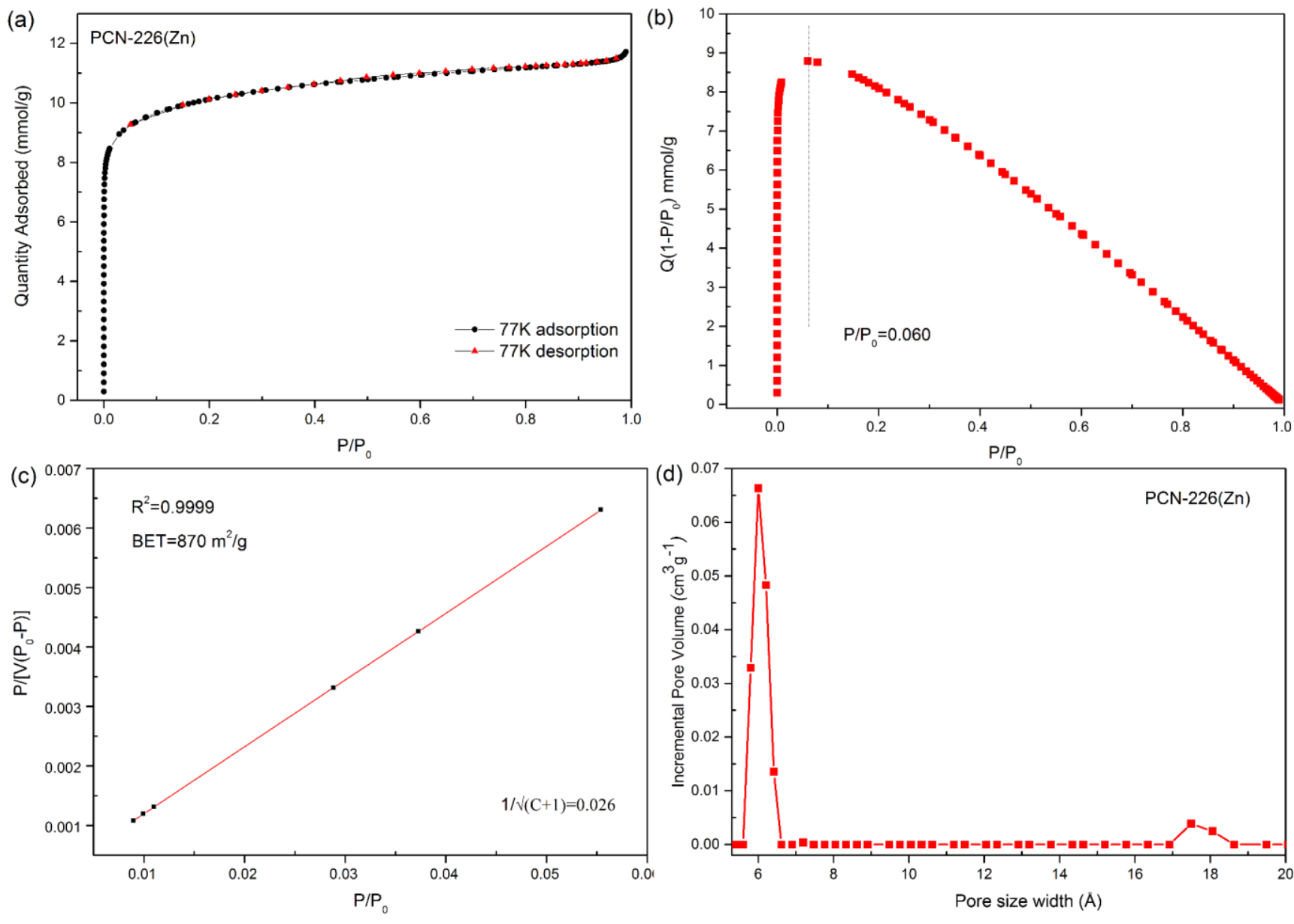

(e)

\begin{tabular}{|l|l|}
\hline $\mathrm{P} / \mathrm{P}_{0}$ Range & $0.0090-0.0554$ \\
\hline Correlation Coefficient & 0.99999 \\
\hline $\mathrm{C}$ & 1513 \\
\hline $\mathrm{Q}_{\mathrm{m}}(\mathrm{mmol} / \mathrm{g})$ & 8.9 \\
\hline $1 \sqrt{ }(C+1)$ & 0.026 \\
\hline BET Surface Area $\left(\mathrm{m}^{2} / \mathrm{g}\right)$ & 870 \\
\hline
\end{tabular}

Figure S11. Porosity analysis of PCN-226(Zn). (a-b) $\mathrm{N}_{2}$ adsorption-desorption isotherms and the analysis of PCN$226(\mathrm{Zn})$ at $77 \mathrm{~K}$. (c) Plot of the linear region of the adsorption $\mathrm{N}_{2}$ isotherm used for the BET equation. (d) Pore size distributions calculated by NLDFT. (e) Summary of parameters in the BET analysis. 

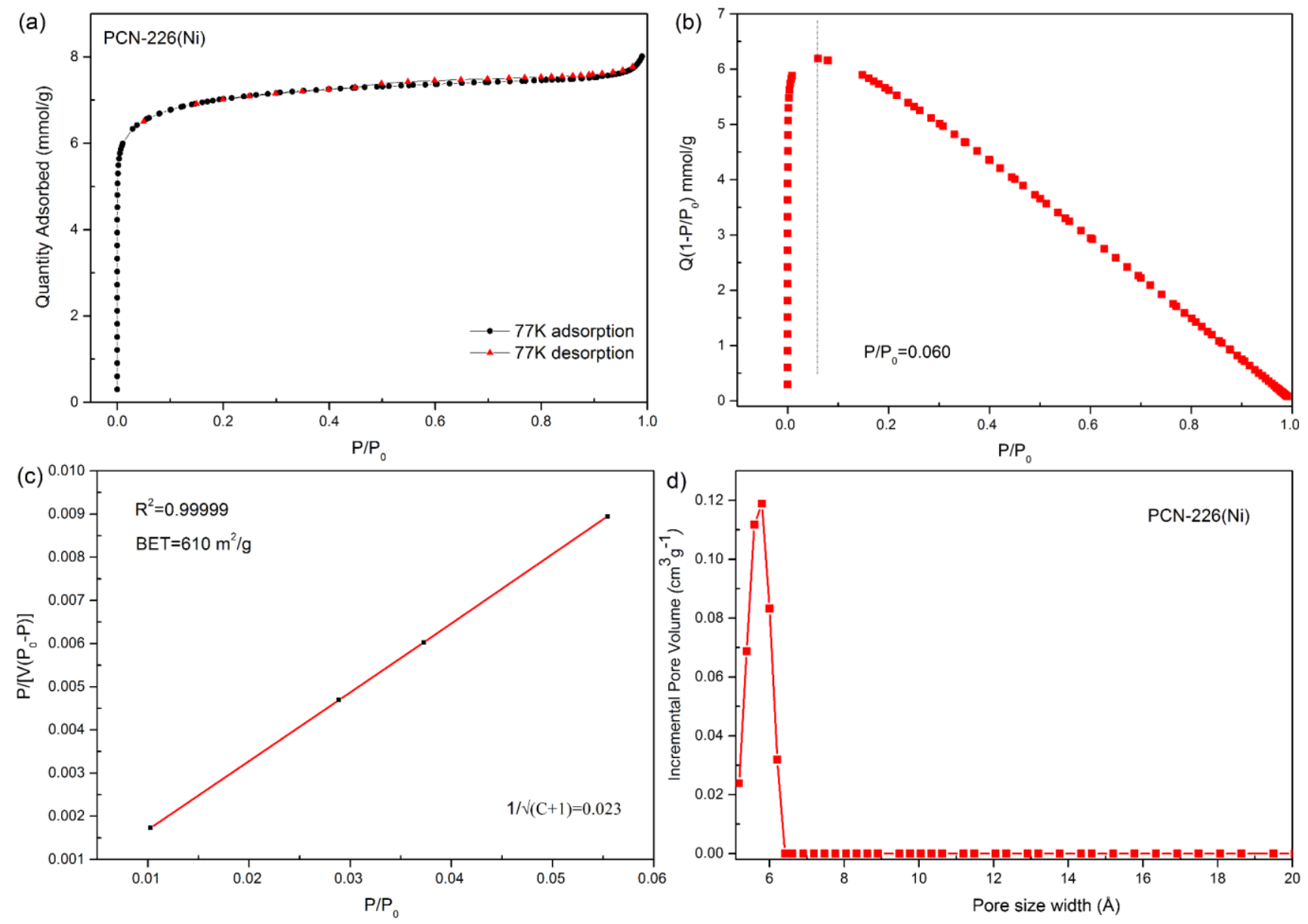

(e)

\begin{tabular}{|l|l|}
\hline $\mathrm{P} / \mathrm{P}_{0}$ Range & $0.0103-0.0554$ \\
\hline Correlation Coefficient & 0.99999 \\
\hline $\mathrm{C}$ & 1920 \\
\hline $\mathrm{Q}_{\mathrm{m}}(\mathrm{mmol} / \mathrm{g})$ & 6.3 \\
\hline $1 \sqrt{ }(C+1)$ & 0.023 \\
\hline BET Surface Area $\left(\mathrm{m}^{2} / \mathrm{g}\right)$ & 610 \\
\hline
\end{tabular}

Figure S12. Porosity analysis of PCN-226(Ni). (a-b) $\mathrm{N}_{2}$ adsorption-desorption isotherms and the analysis of PCN$226(\mathrm{Ni})$ at $77 \mathrm{~K}$. (c) Plot of the linear region of the adsorption $\mathrm{N}_{2}$ isotherm used for the BET equation. (d) Pore size distributions calculated by NLDFT. (e) Summary of parameters in the BET analysis. 


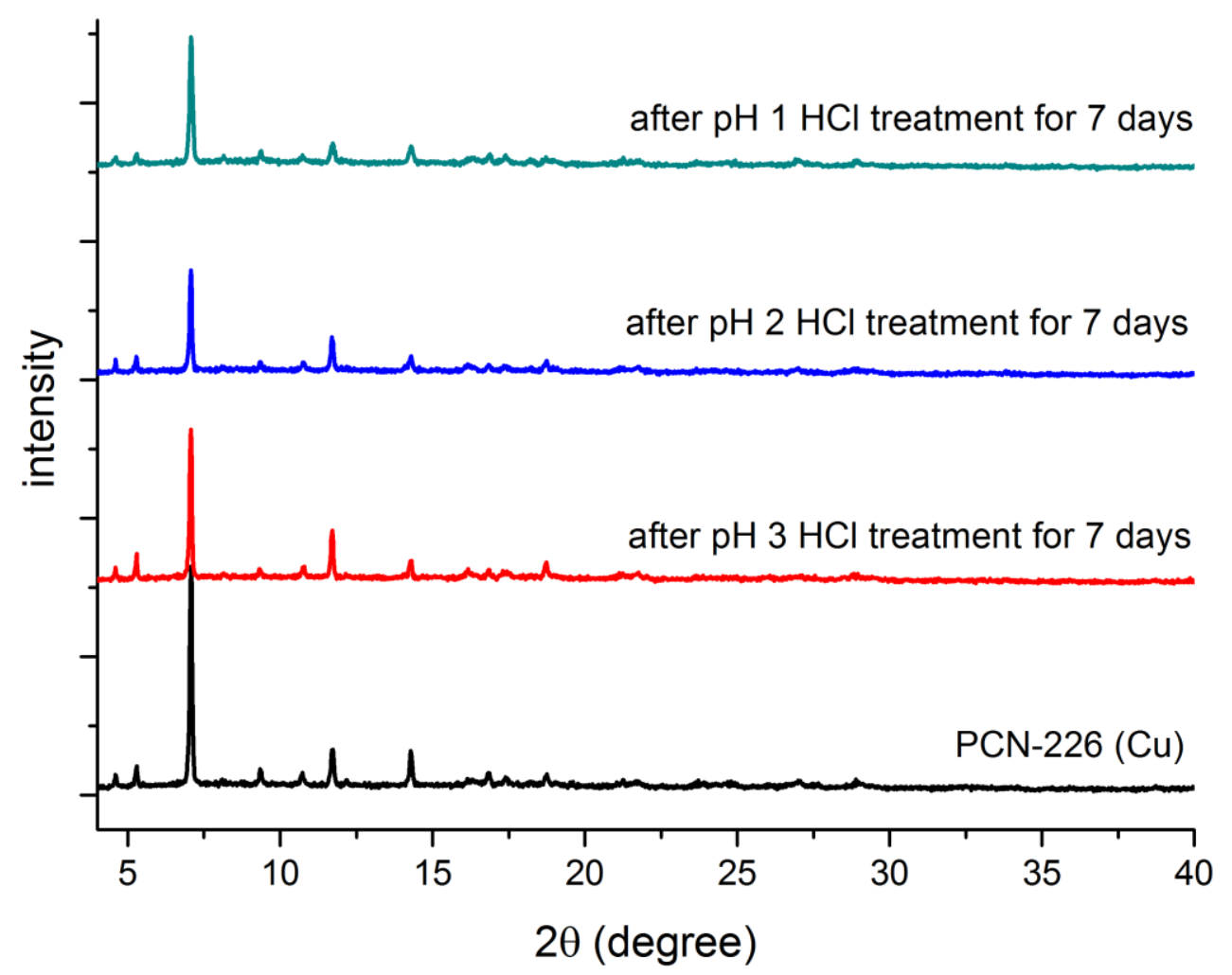

Figure S13. PXRD patterns of PCN $-226(\mathrm{Cu})$ after being treated in acid solutions for 7 days, showing little alteration. This suggests that the structure is well preserved after the treatment.

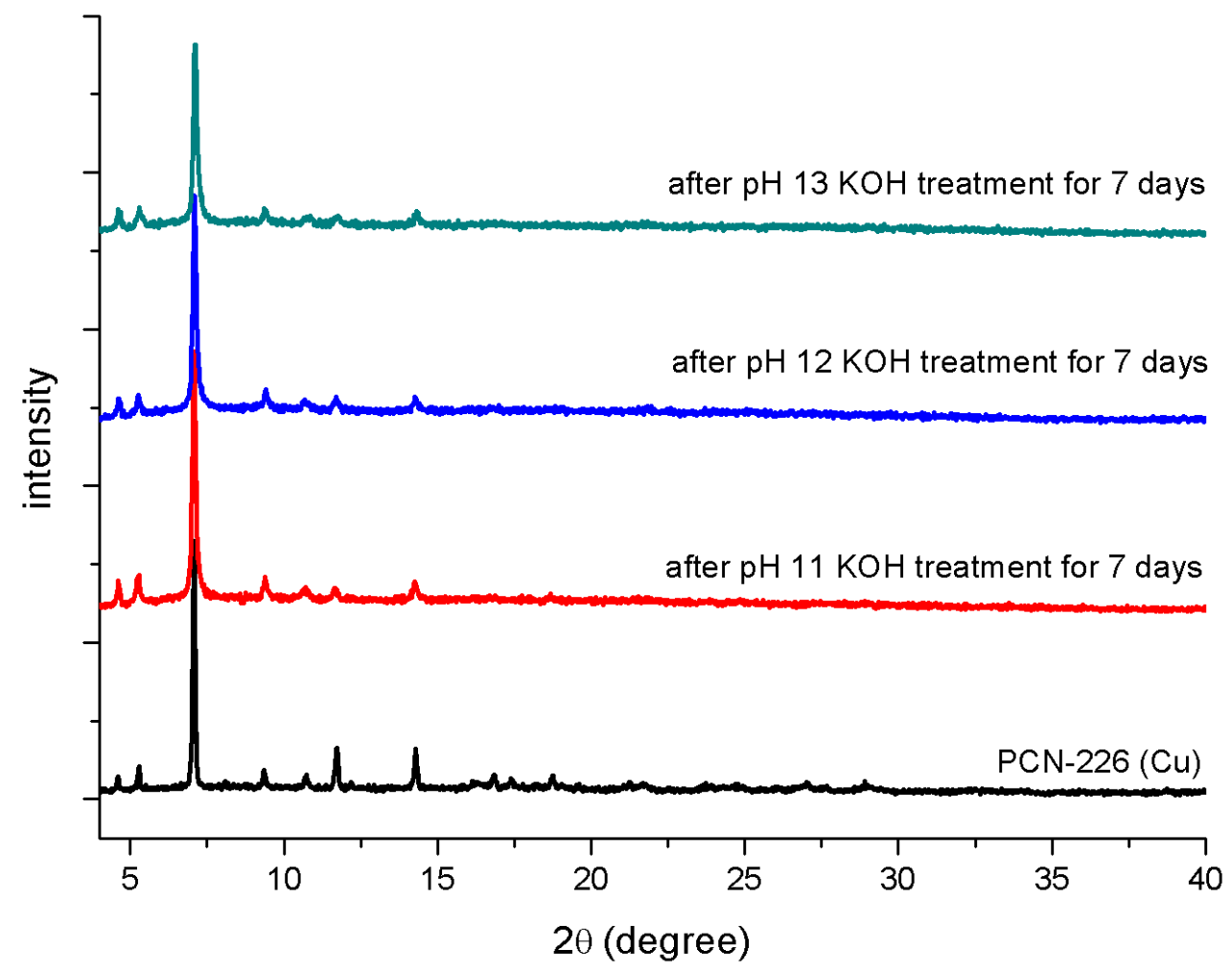

Figure S14. PXRD patterns of PCN-226(Cu) after being treated in base solutions for 7 days, showing little alteration. This suggests that the structure is well preserved after the treatment. 


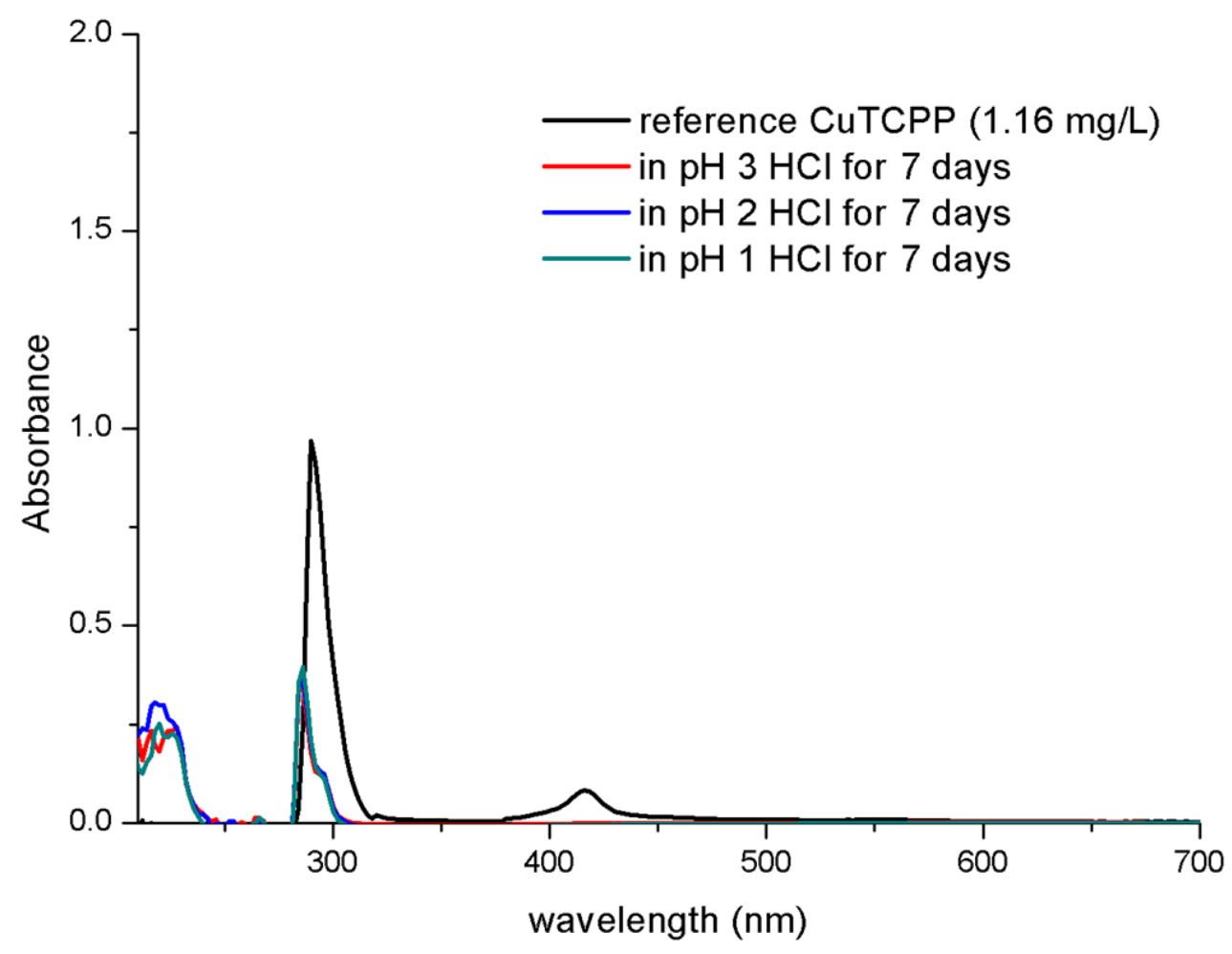

Figure S15. UV-Vis spectra of PCN-226(Cu) after being treated in acid solutions pH for 7 days. As compared to reference spectrum, the leached CuTCPP amount is $0.02 \%$ upon the treatment.

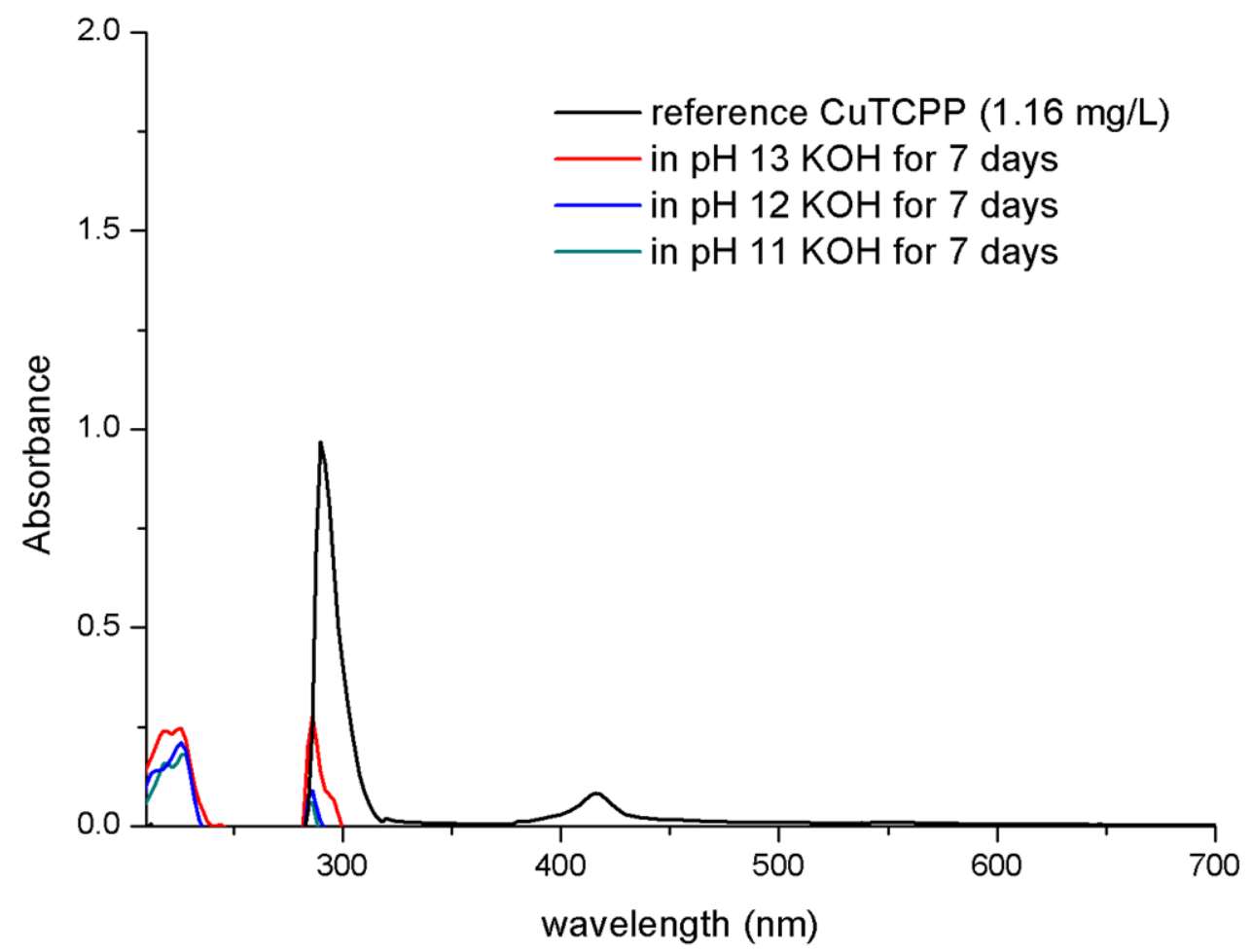

Figure S16. UV-Vis spectra of PCN-226(Cu) after being treated in base solution $\mathrm{pH}$ for 7 days. As compared to reference spectrum, the leached CuTCPP amount is $0.017 \%$ upon the treatment. 


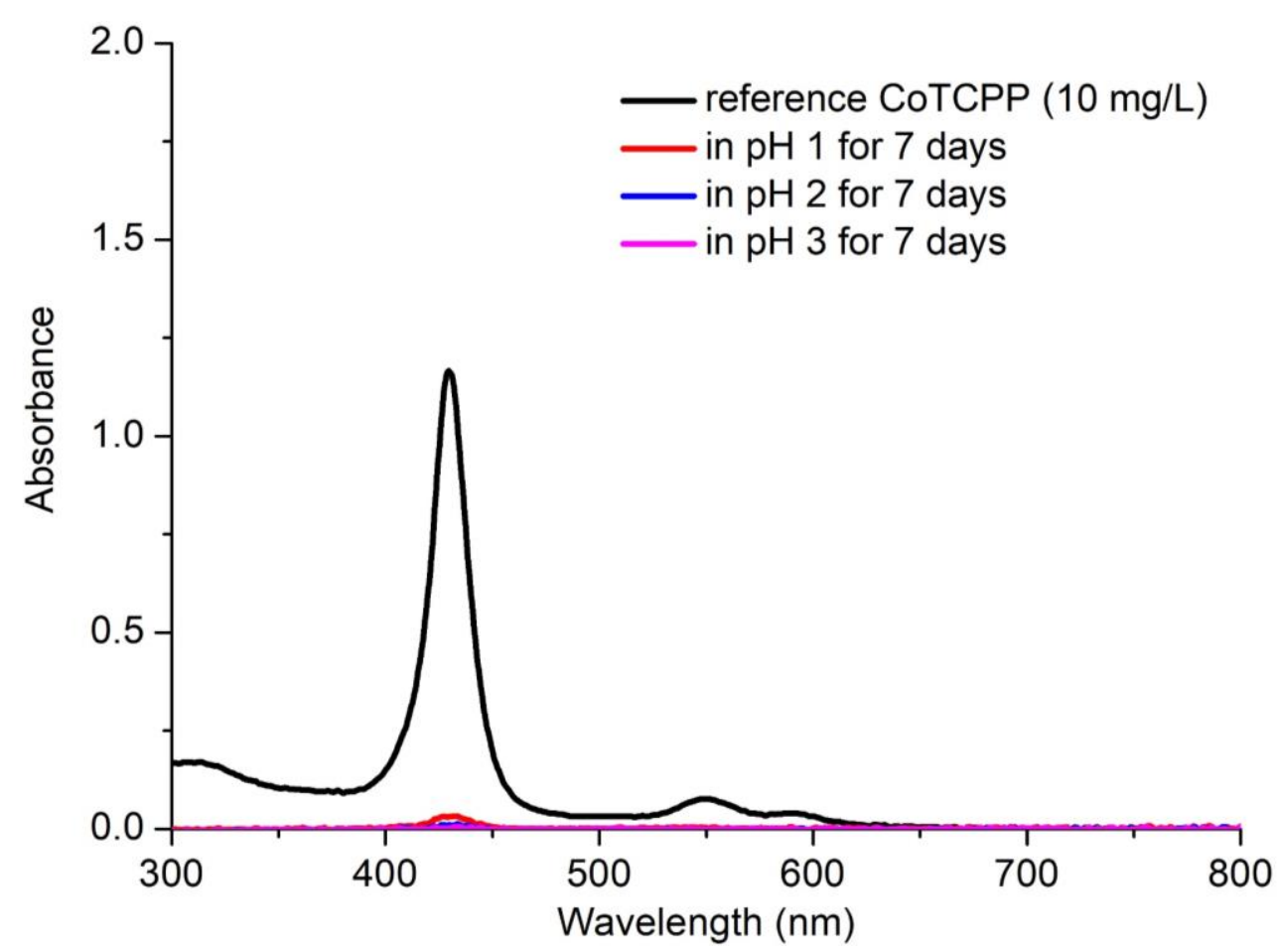

Figure S17. UV-Vis spectra of PCN-226(Co) after being treated in acid solution pH for 7 days. As compared to reference spectrum, the leached CoTCPP amount is $0.21 \%$ upon the treatment.

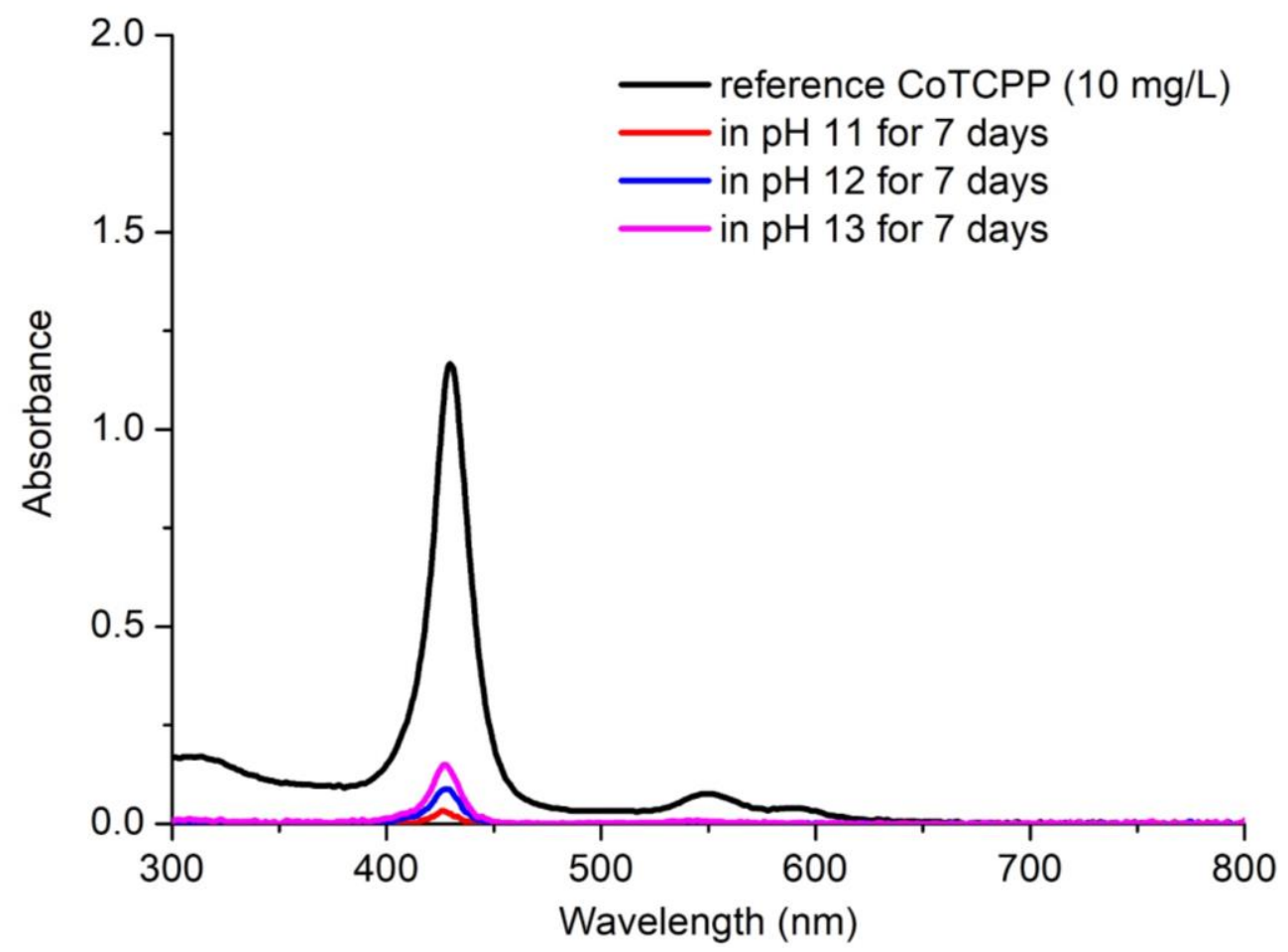

Figure S18. UV-Vis spectra of $\mathrm{PCN}-226(\mathrm{Co})$ after being treated in base solution $\mathrm{pH}$ for 7 days. As compared to reference spectrum, the leached CoTCPP amount is $0.97 \%$ upon the treatment. 


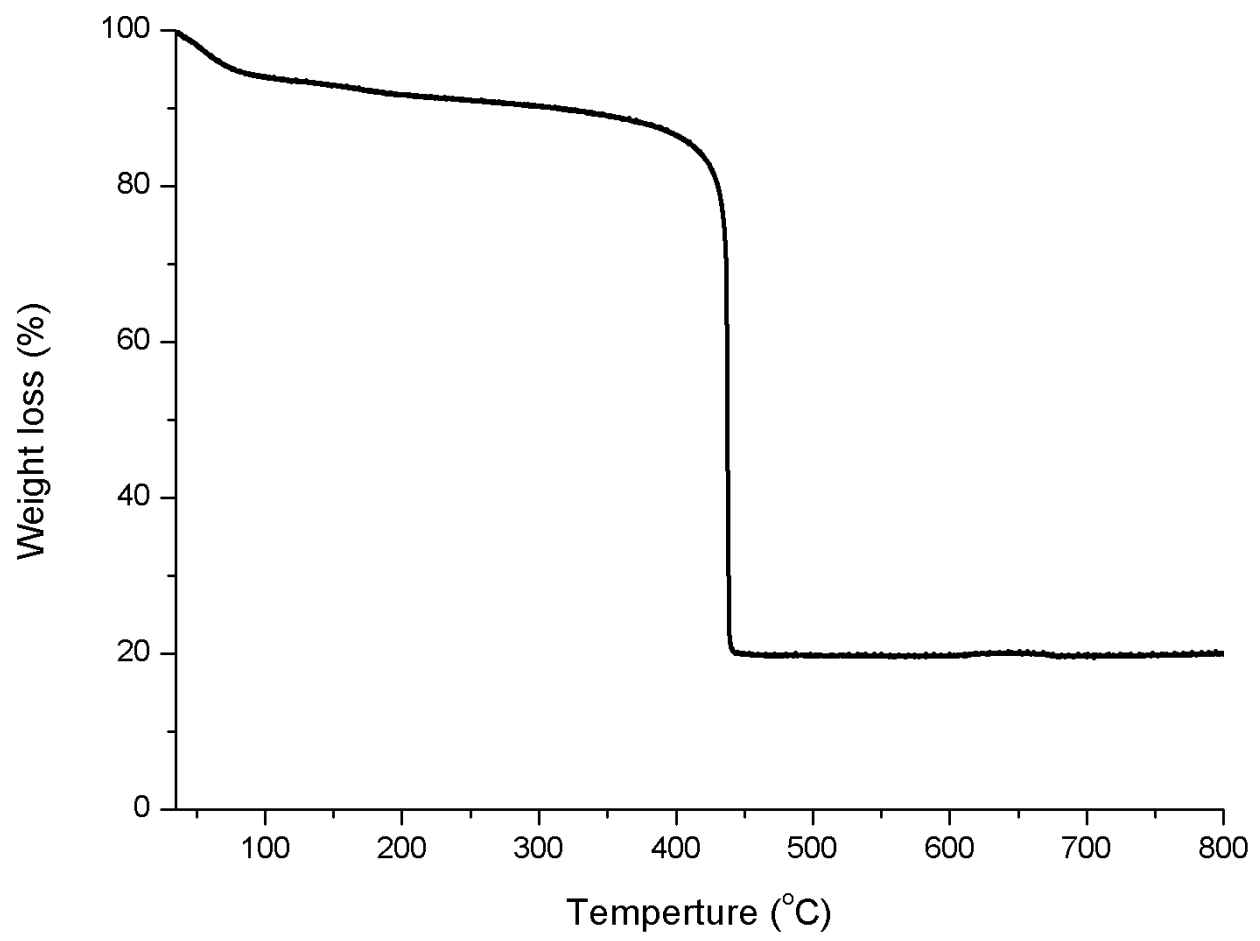

Figure S19. Thermogravimetric analysis of $\mathrm{PCN}-226(\mathrm{Cu})$ under $\mathrm{N}_{2}$ with a heating rate of $10{ }^{\circ} \mathrm{C} \min ^{-1}$. The first weight loss up to ca. $100{ }^{\circ} \mathrm{C}$ is due to the removal of guest molecules. The sharp weight loss at ca. $430{ }^{\circ} \mathrm{C}$ is due to the combustion of linkers.

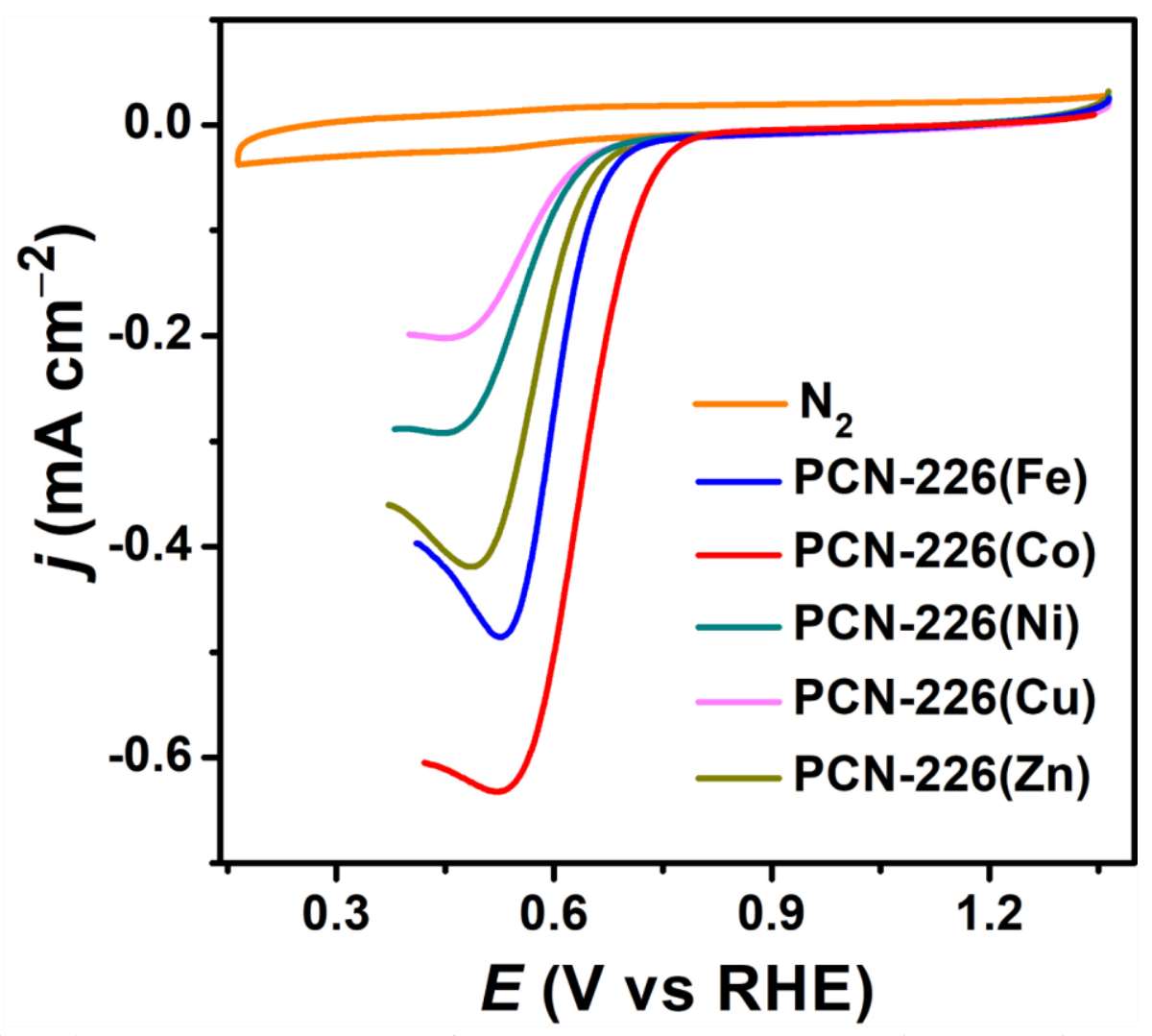

Figure S20. Cyclic voltammetry (CV) curves of PCN-226(M) $(\mathrm{M}=\mathrm{Fe}, \mathrm{Co}, \mathrm{Ni}, \mathrm{Cu}, \mathrm{Zn})$ in $0.1 \mathrm{M} \mathrm{KOH}$ solution saturated by $\mathrm{N}_{2}$ and $\mathrm{O}_{2}$, respectively, without using any carbon additives. It shows an electroactivity order of Co > $\mathrm{Fe}>\mathrm{Zn}>\mathrm{Cu} \approx \mathrm{Ni}$. 


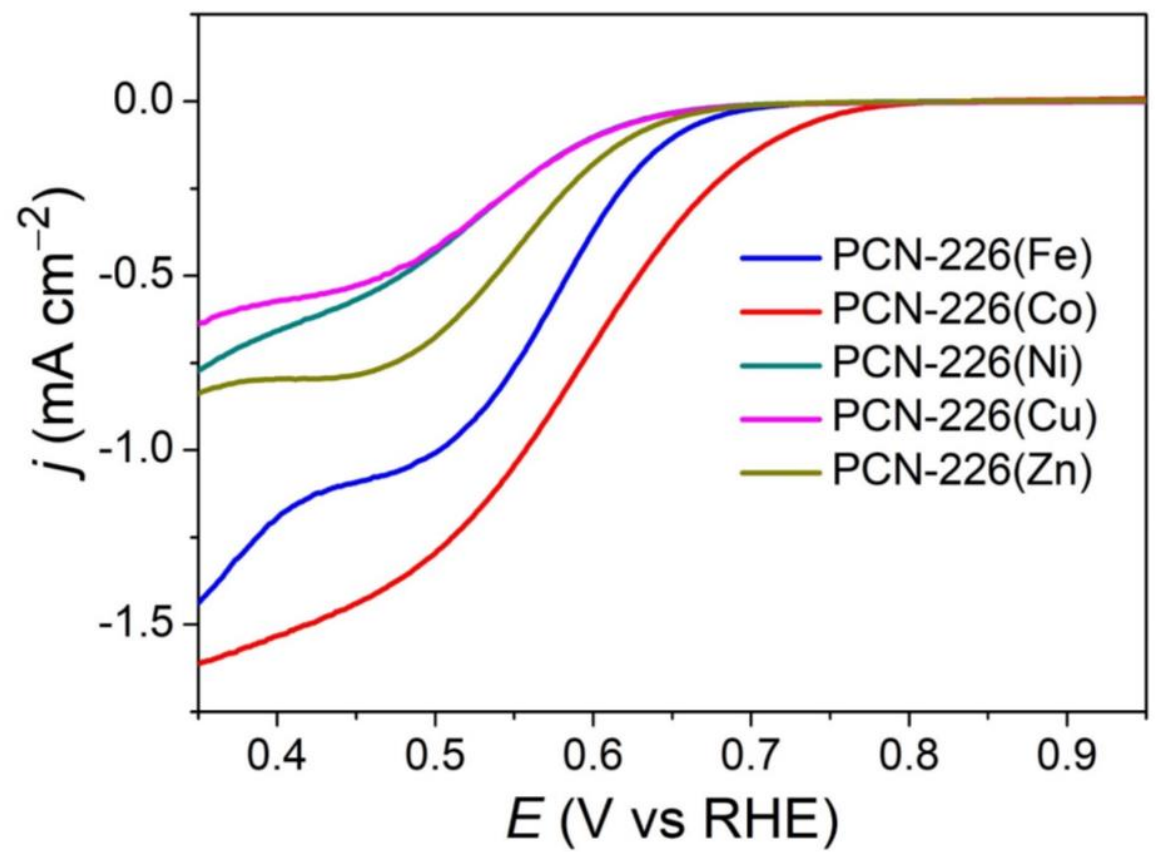

Figure S21. LSV curves of $\mathrm{PCN}-226(\mathrm{M})(\mathrm{M}=\mathrm{Fe}, \mathrm{Co}, \mathrm{Ni}, \mathrm{Cu}, \mathrm{Zn})$ in $\mathrm{O}_{2}$-saturated $0.1 \mathrm{M} \mathrm{KOH}$ solution at atating rate of $1600 \mathrm{rpm}$ and a scan rate of $10 \mathrm{mV} \mathrm{s}^{-1}$, without using any carbon additives.

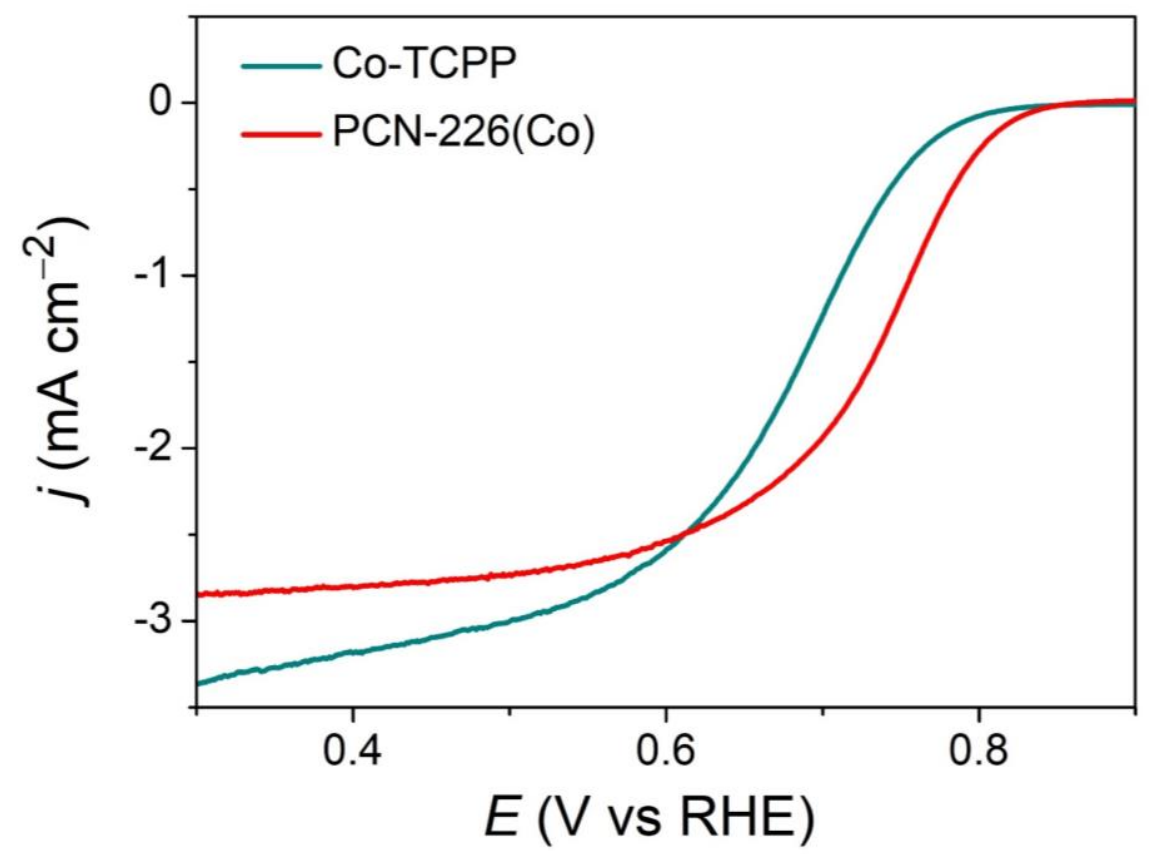

Figure S22. LSV curves of Co-TCPP and PCN-226(Co) measured in $0.1 \mathrm{M} \mathrm{KOH}$ with the same amount of Co porphyrin. As compared to molecular catalyst Co-TCPP, it shows PCN-226(Co) has an improved ORR performance as large as $50 \mathrm{mV}$ for $E_{1 / 2}$ by limiting deactivation pathways. 


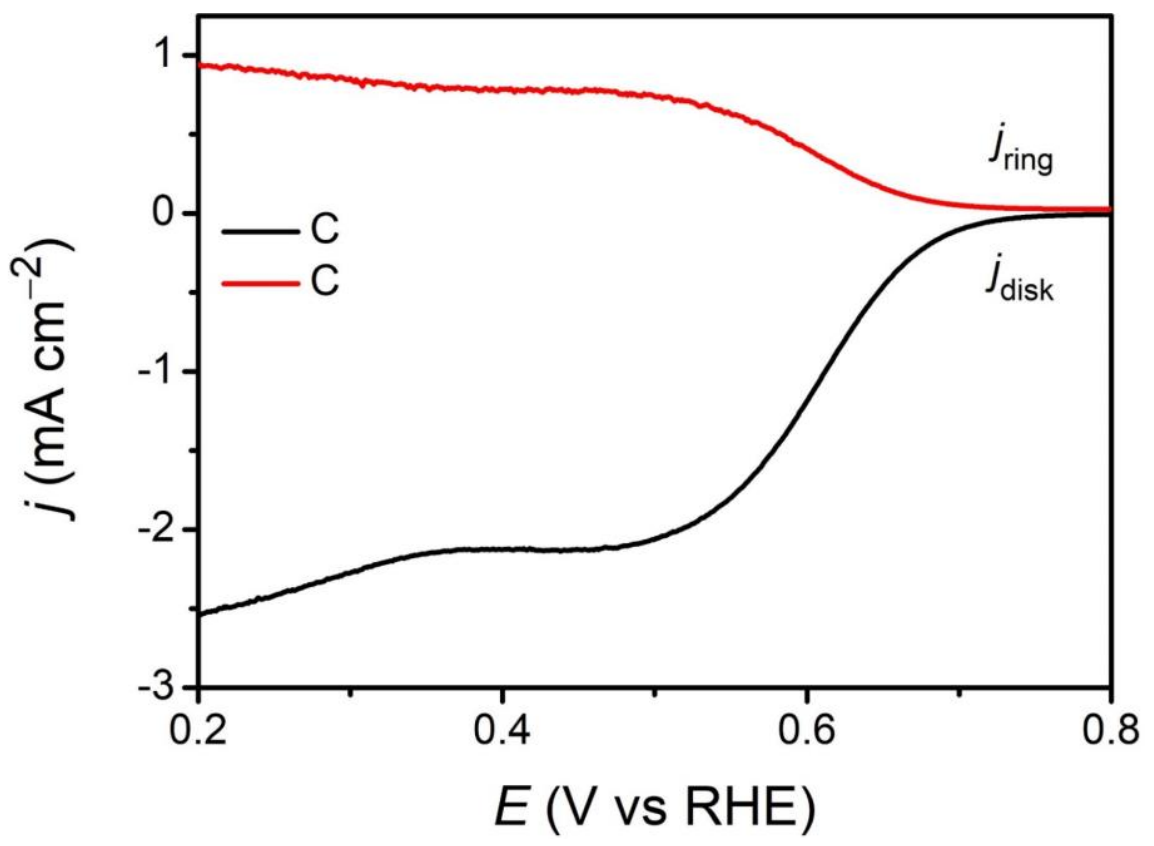

Figure S23. LSV curves of the carbon black in $\mathrm{O}_{2}$-saturated $0.1 \mathrm{M} \mathrm{KOH}$ solution at a scan rate of $10 \mathrm{mV} \mathrm{s}^{-1}$ and an electrode rotation speed of $1600 \mathrm{rpm}$.

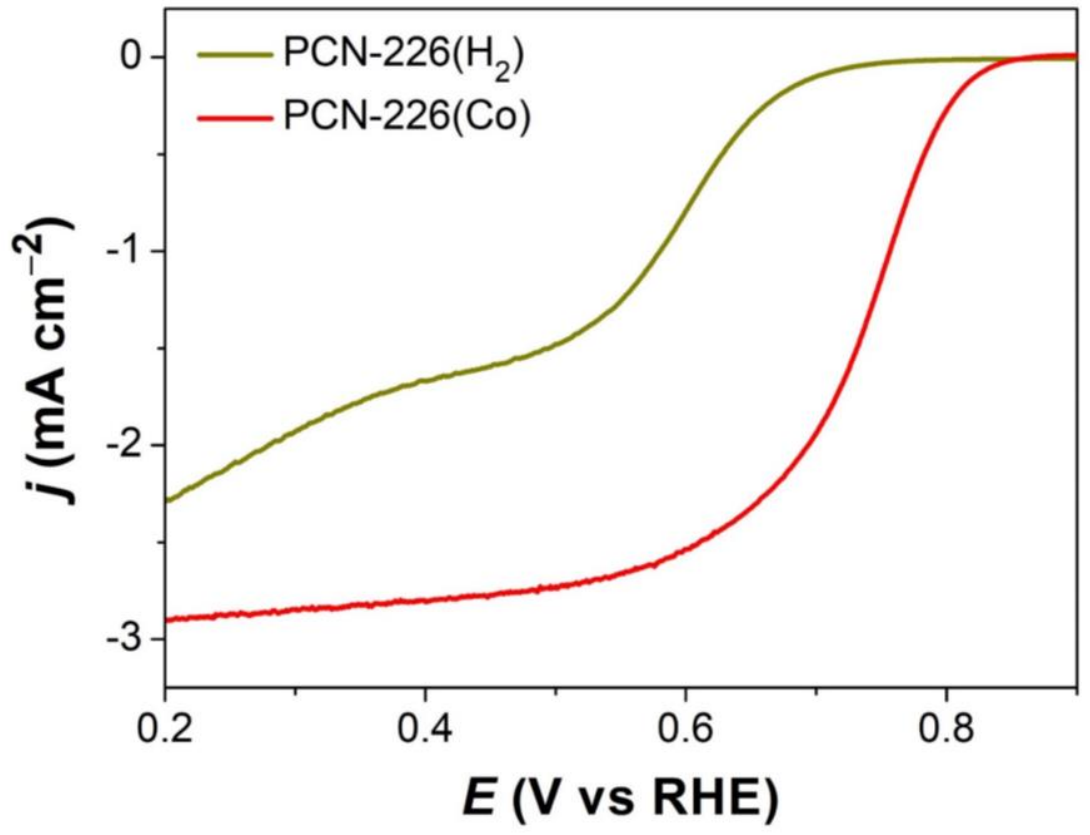

Figure S24. LSV curves of PCN-226( $\left.\mathrm{H}_{2}\right)$ and $\mathrm{PCN}-226(\mathrm{Co})$. 


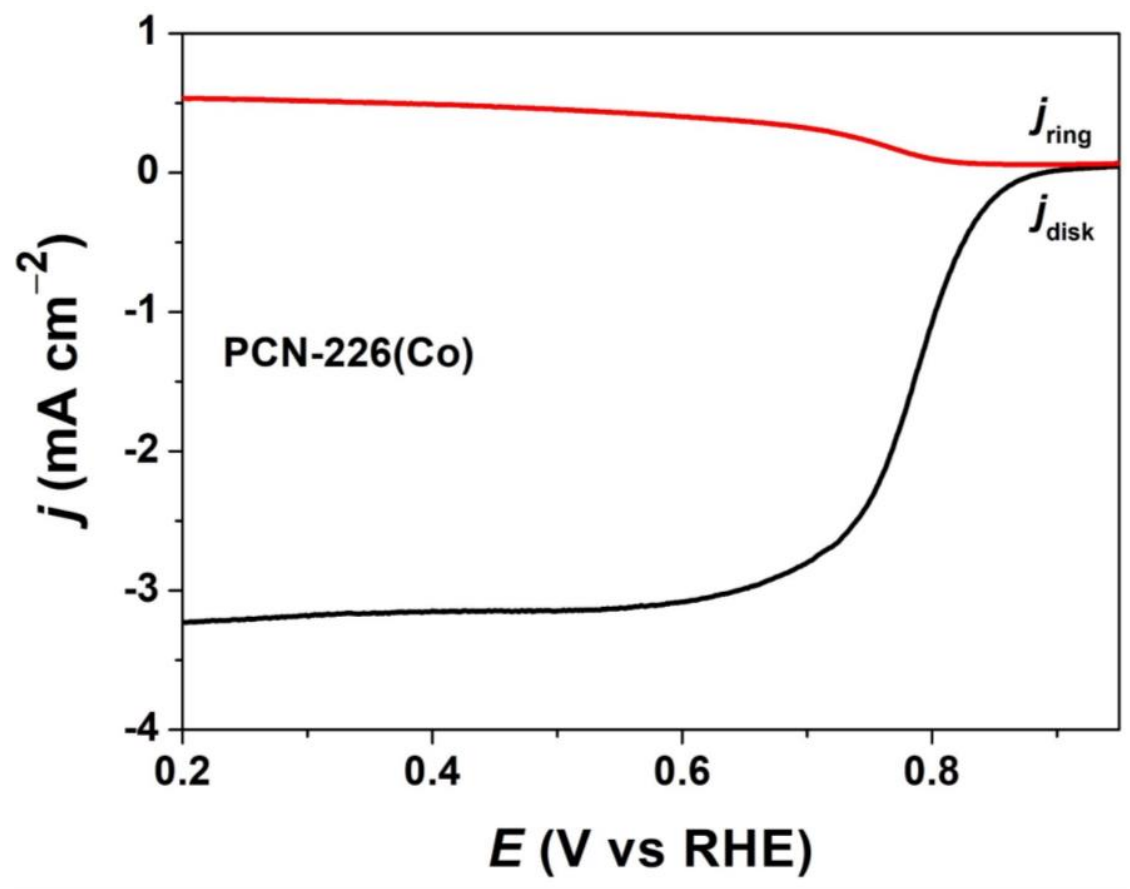

Figure S25. LSV curves of PCN-226(Co) measured with RRDE, using a catalyst loading of $0.32 \mathrm{mg} \mathrm{cm}^{-2}$. Increasing the loading from $0.08 \mathrm{mg} \mathrm{cm}^{-2}$, the half-wave potential was subsequently increased from $0.75 \mathrm{~V}$ to $0.79 \mathrm{~V}$ (vs RHE).

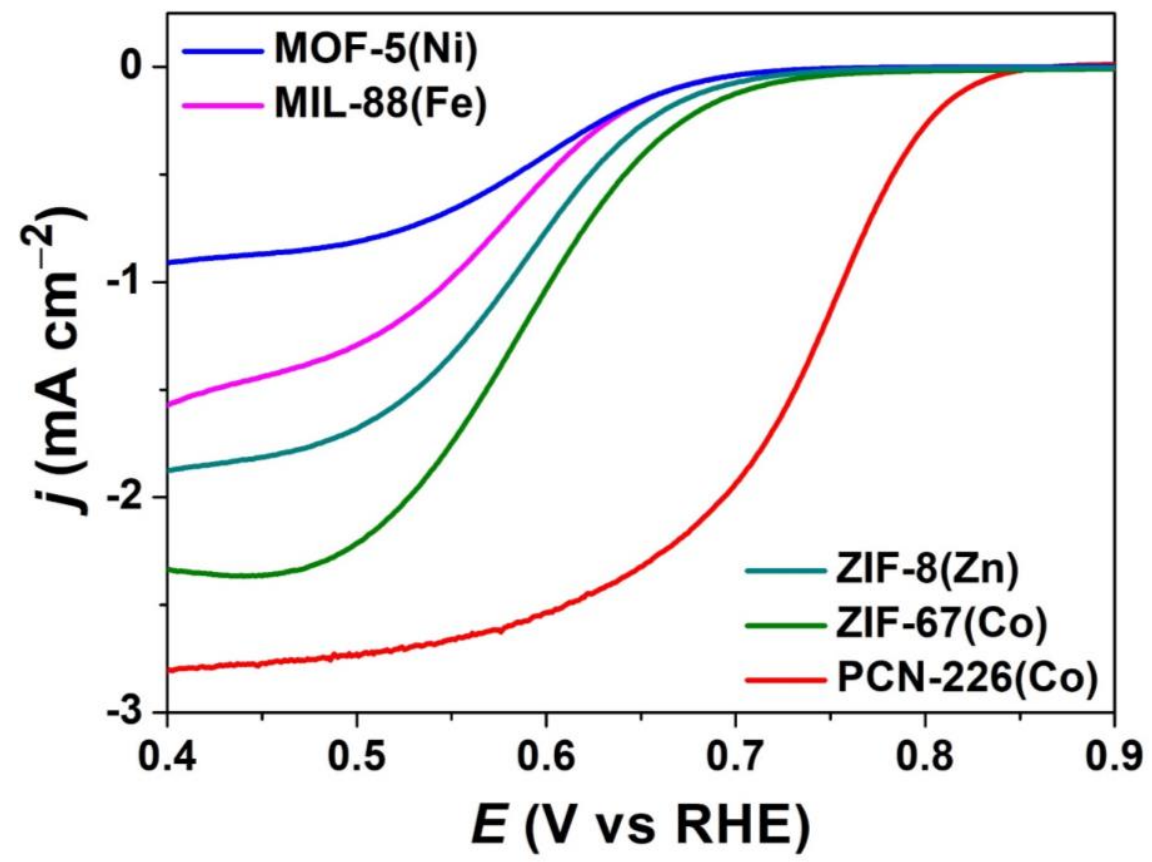

Figure S26. Comparison of LSV curves for PCN-226(Co) and reported MOFs including MIL-88(Fe), ZIF-67(Co), MOF-5(Ni), and ZIF-8(Zn). 


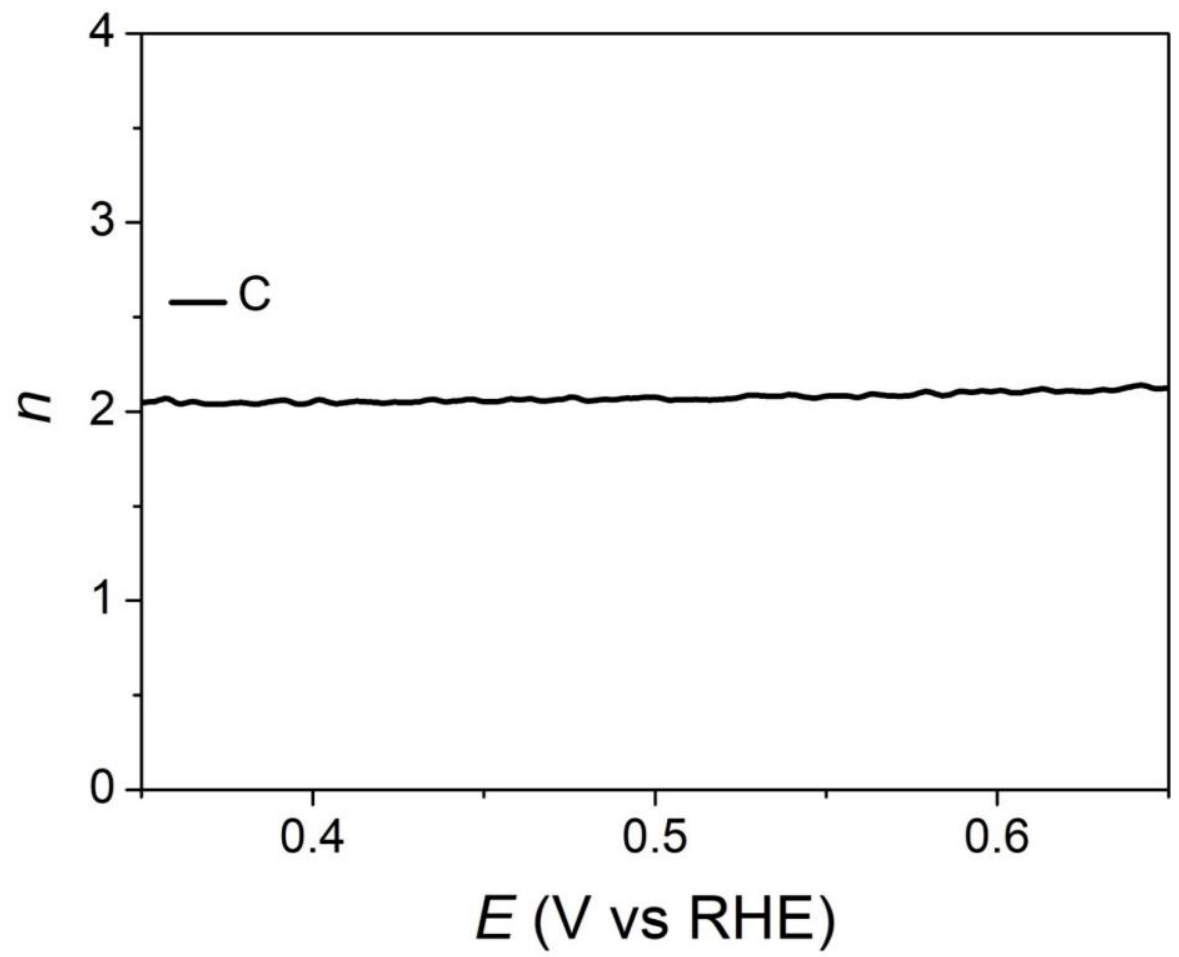

Figure S27. Electron transfer numbers $(n)$ of the carbon black versus potential.

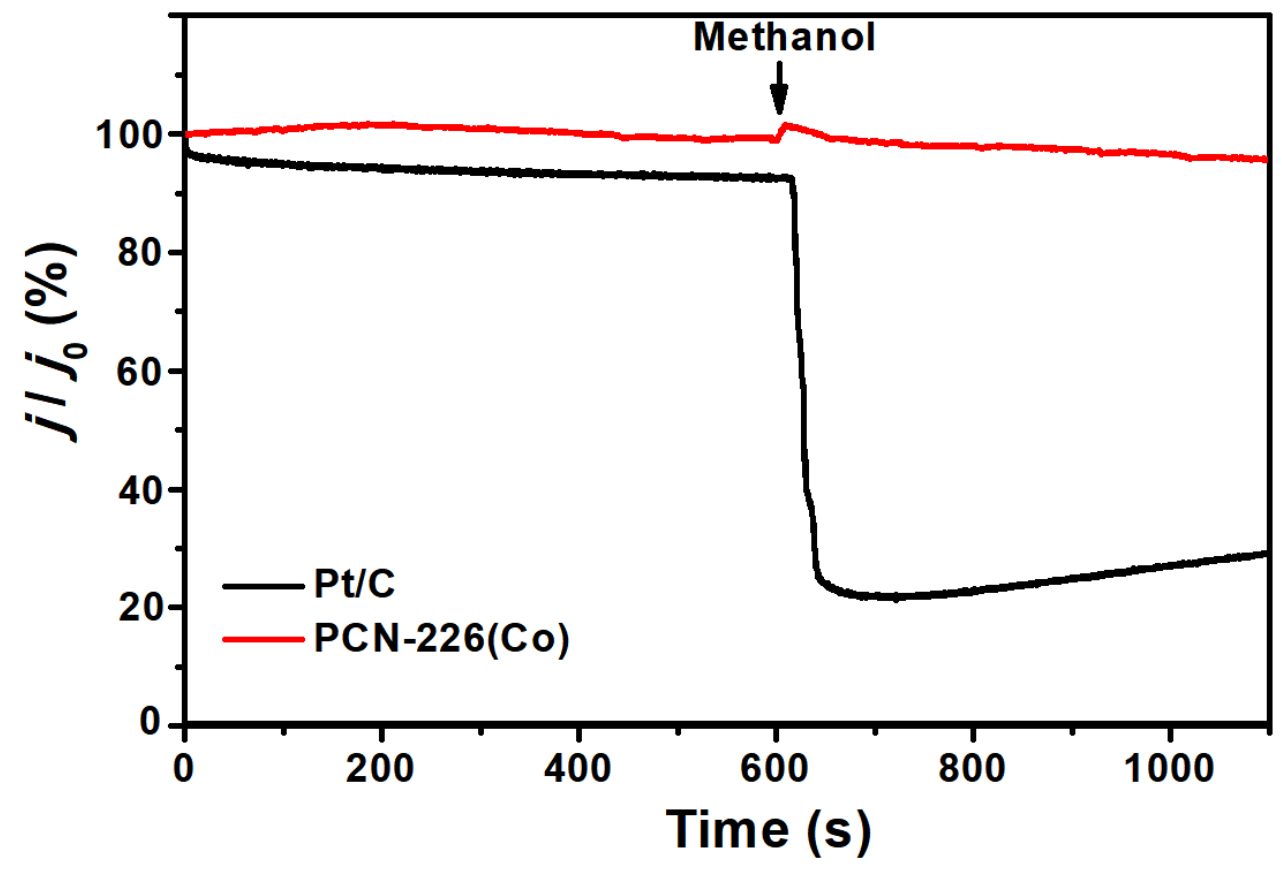

Figure S28. Current-time ( $j$-t) chronoamperometric responses with 5\% (v/v) methanol addition at $\sim 600 \mathrm{~s}$ measured at $1600 \mathrm{rpm}$ in $\mathrm{O}_{2}$-saturated $0.1 \mathrm{M} \mathrm{KOH}$. 


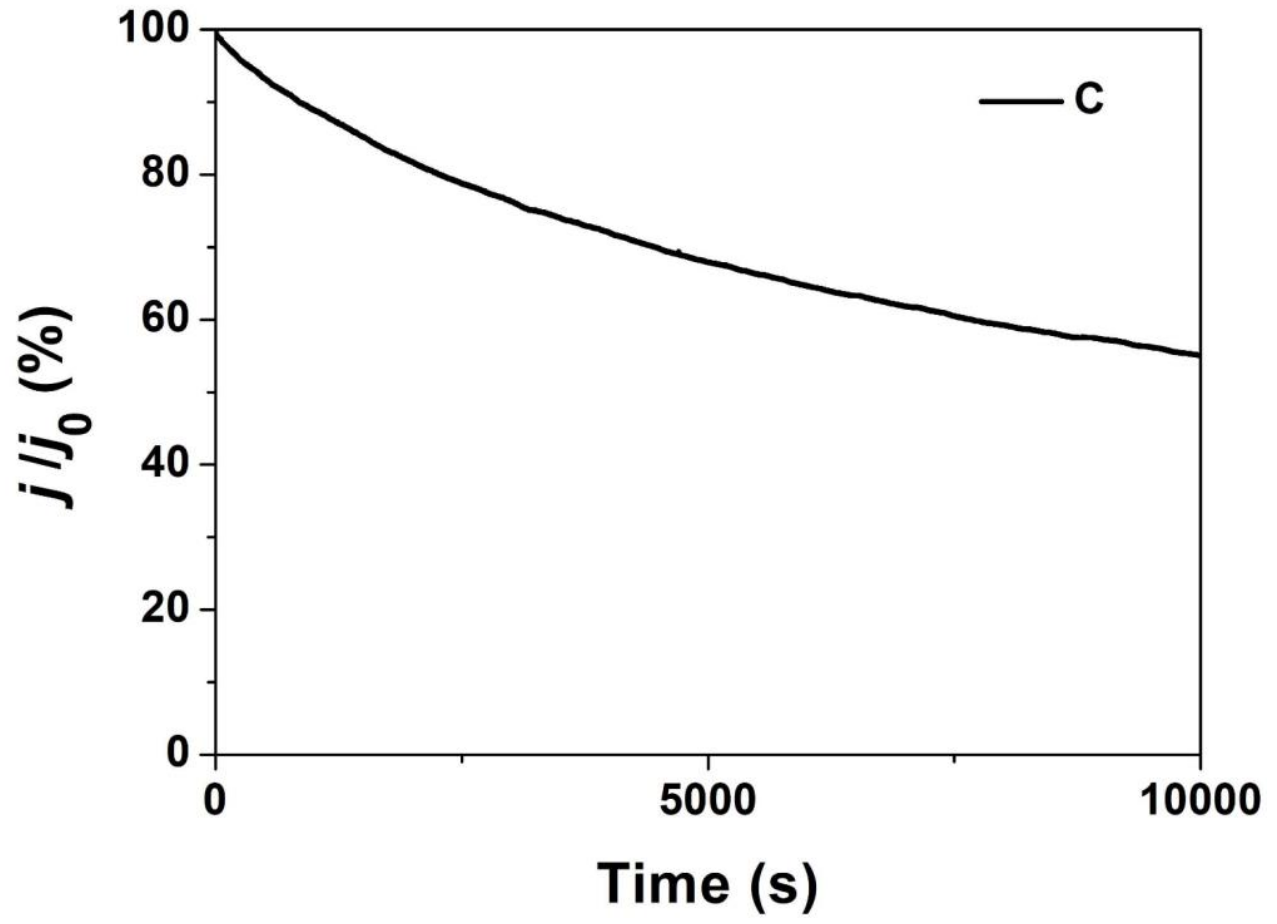

Figure S29. Durability test for $\mathrm{C}$ at $0.46 \mathrm{~V}$ (vs. RHE) and $1600 \mathrm{rpm}$ in $\mathrm{O}_{2}$-saturated $0.1 \mathrm{M} \mathrm{KOH}$ solution. $j_{0}$ is the initial current.

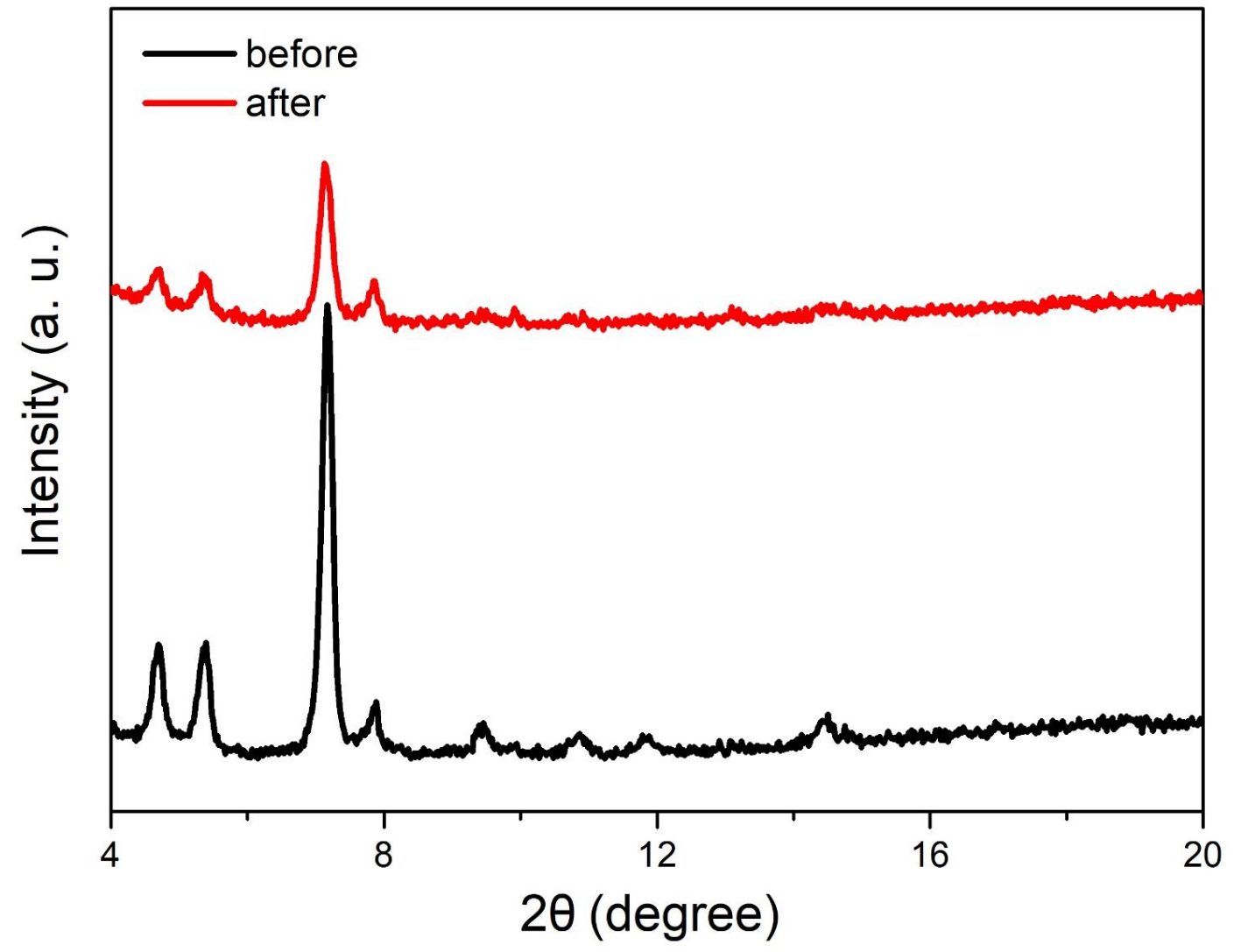

Figure S30. PXRD patterns of PCN-226(Co) before (black) and after (red) electrochemical stability test. 

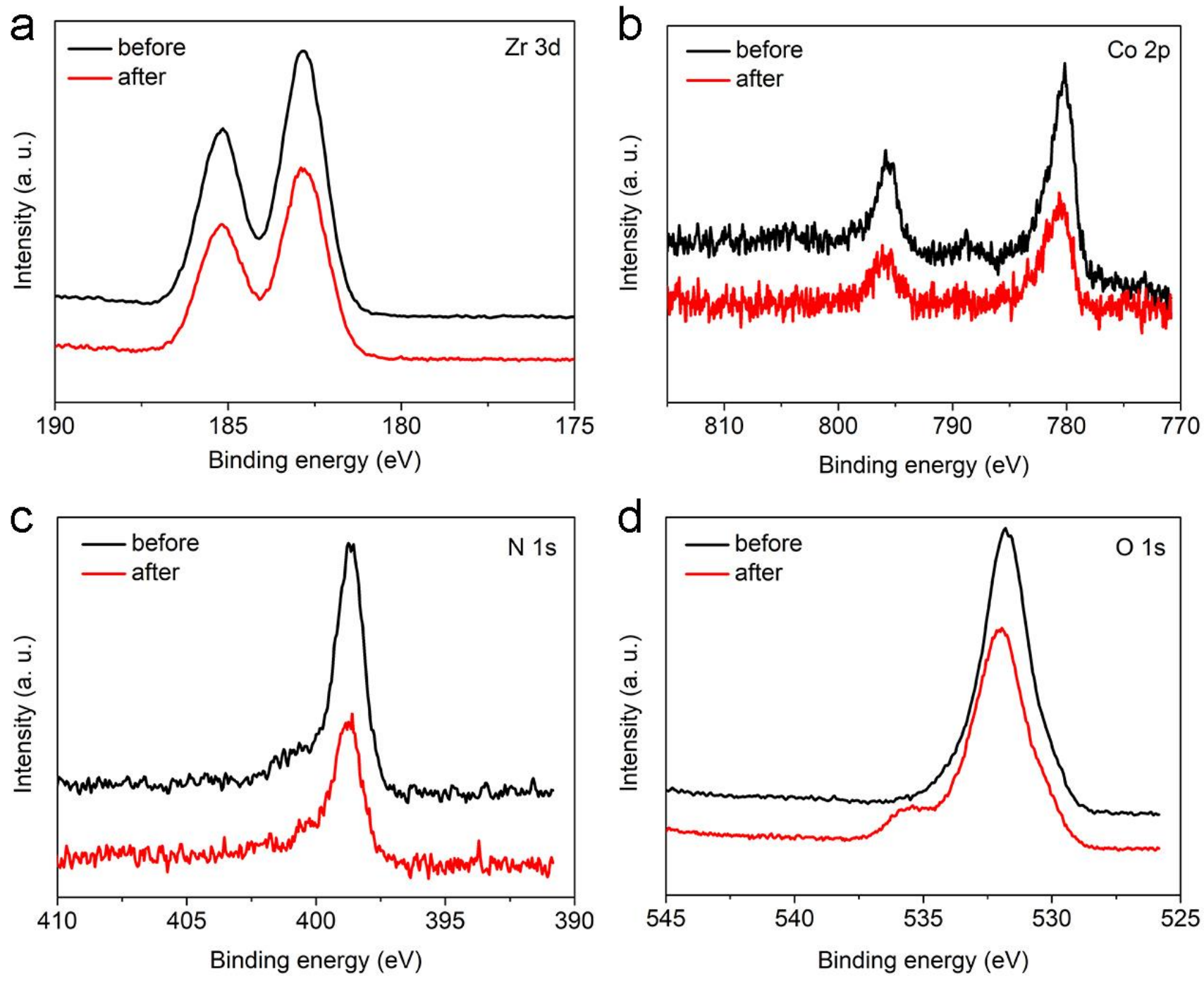

Figure S31. High-resolution XPS spectra of Zr 3d (a), Co 2p (b), N 1s (c), and O 1s (d) for PCN-226(Co) before and after electrochemical stability test. After the stability test, it shows a 3.27 molar ratio of $\mathrm{Zr} / \mathrm{Co}$, which is similar to the ratio of 3.44 before the test, showing the composition of PCN-226(Co) remains unchanged.
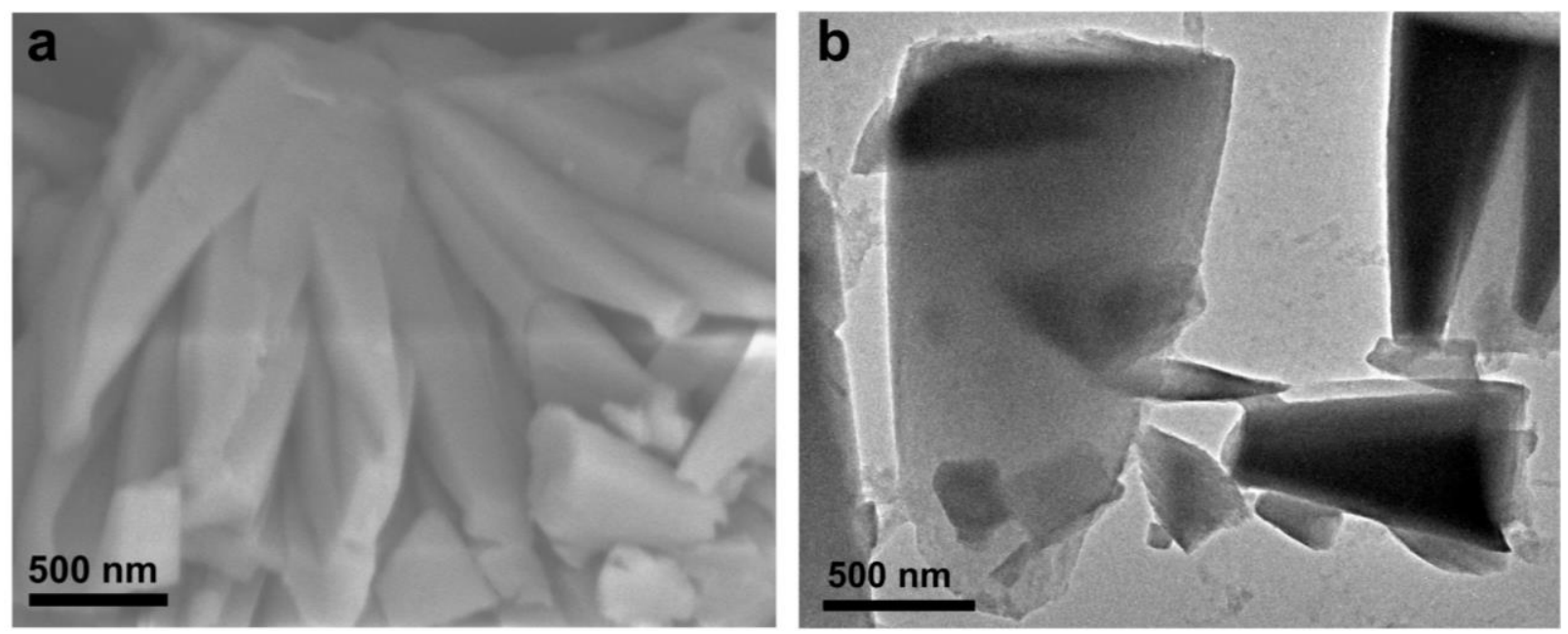

Figure S32. SEM (a) and TEM (b) images of PCN-226(Co) after electrochemical stability test. 

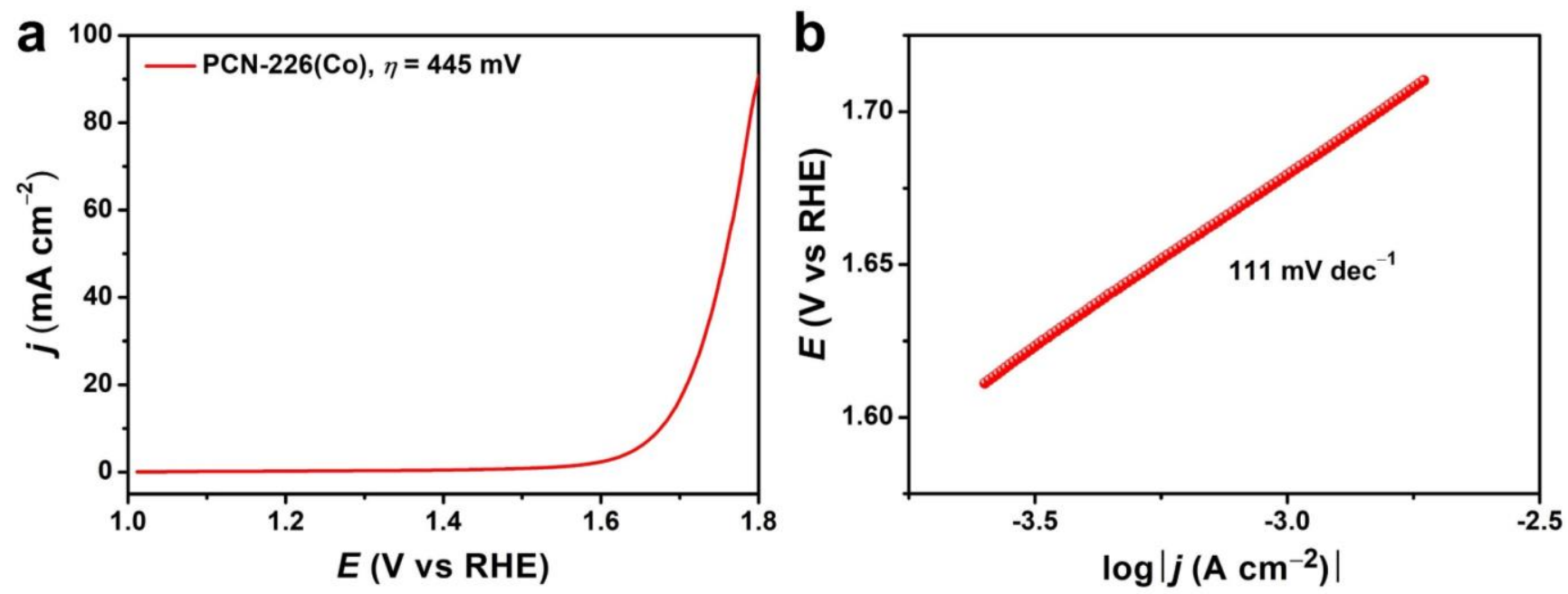

Figure S33. (a) LSV curve of PCN-226(Co) for OER measured with a scan rate of $10 \mathrm{mV} \mathrm{s}^{-1}$. (b) Tafel plots of PCN-226(Co) for OER measured with a scan rate of $2 \mathrm{mV} \mathrm{s}^{-1}$ on a glassy carbon electrode $\left(0.07 \mathrm{~cm}^{2}\right)$ in $1.0 \mathrm{M}$ $\mathrm{KOH}$.

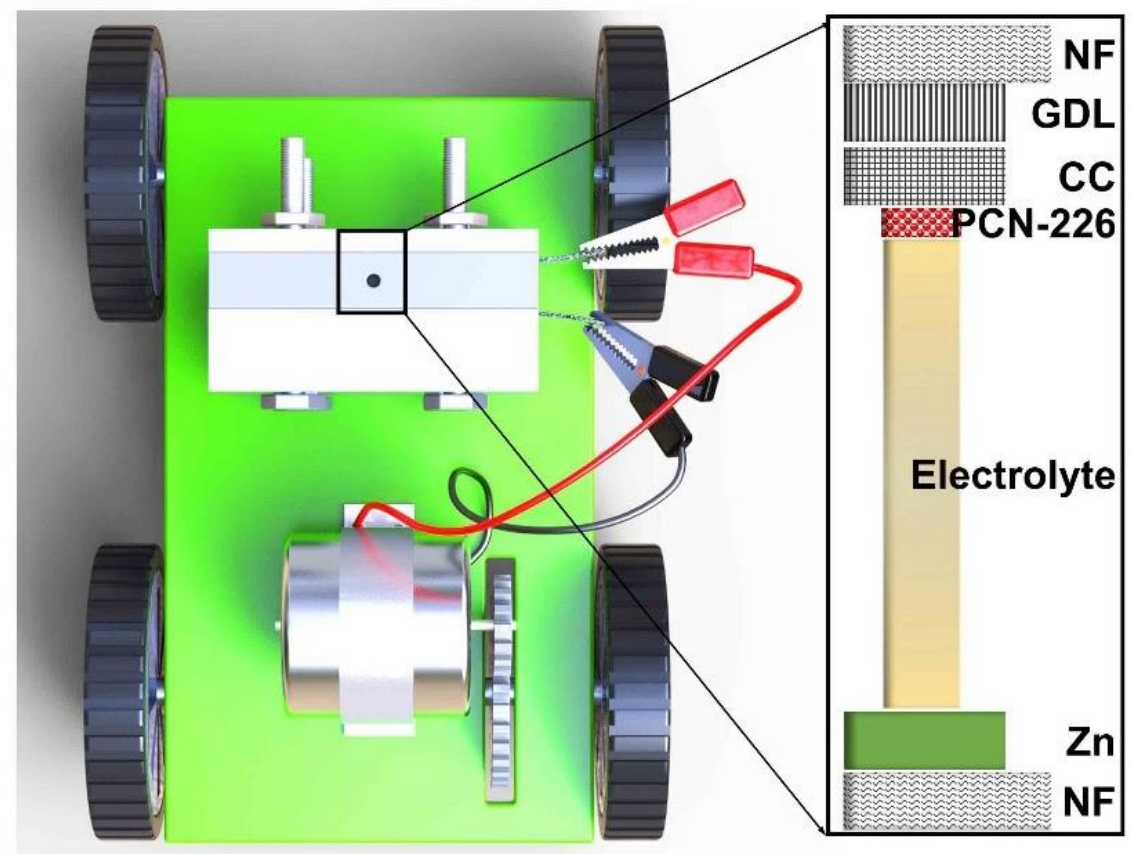

Figure S34. Photograph of a Zn-air battery powered mini car. The Zn-air battery was assembled with Ni foam (NF), gas diffusion layer (GDL), carbon cloth (CC), PCN-226 (Co) catalysts, electrolyte, and Zn plate. More information is given in the Movie $\mathrm{S} 1$. 


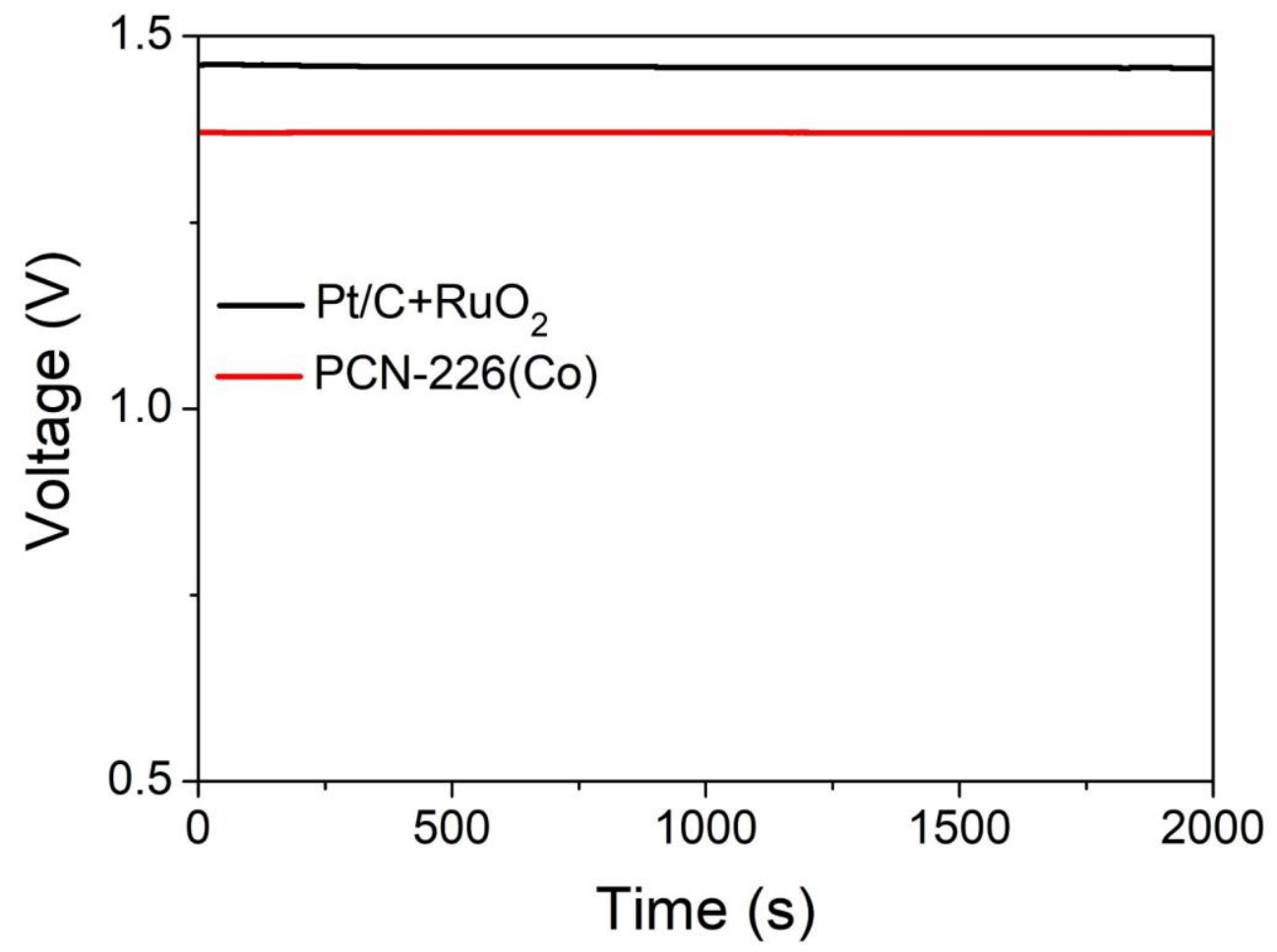

Figure S35. The open-circuit voltage of $\mathrm{PCN}-226(\mathrm{Co})$ and $\mathrm{Pt} / \mathrm{C}+\mathrm{RuO}_{2}$.

Table S1. Crystallographic data and Pawley fit results of PCN-226(Cu).

\begin{tabular}{ll}
\hline Chemical formula & $\mathrm{C}_{248} \mathrm{Cu}_{4} \mathrm{~N}_{16} \mathrm{O}_{64} \mathrm{Zr}_{12}$ \\
Formula weight & 5575.48 \\
\hline Crystal system & Orthorhombic \\
Space group & Ibam $(\mathrm{No.} .72)$ \\
$a / \AA$ & $37.319(4)$ \\
$b / \AA$ & $11.628(11)$ \\
$c / \AA$ & $33.058(3)$ \\
Temperature/K & $298(2)$ \\
Wavelength/A & 1.54056 \\
$2 \theta$ range/ & \\
$\mathrm{R}_{p}$ & $3.00047-45.00424$ \\
$\mathrm{R}_{w p}$ & 0.0699 \\
$\mathrm{R}_{\text {exp }}$ & 0.0925 \\
$\mathrm{GOOF}$ & 0.0727 \\
\hline
\end{tabular}


Table S2. Experimental details from $c$ RED collection of the dataset of PCN-226(Cu).

\begin{tabular}{ll}
\hline$\lambda(\AA)$ & $0.0251(200 \mathrm{keV})$ \\
Rotation step $\left(^{\circ}\right)$ & 0.245 \\
Tilt range $\left(^{\circ}\right)$ & 60.5 to $-47.6(108.1$ in total $)$ \\
No. of images & 432 \\
Exposure time $\left(\mathrm{s}\right.$ frame $\left.{ }^{-1}\right)$ & 0.5 \\
Total data collection time $(\mathrm{s})$ & 216 \\
Beam current & $<0.01 \mathrm{pA}$ \\
Camera length $(\mathrm{mm})$ & 400 \\
\hline
\end{tabular}

Table S3. Crystallographic details for the refinement of PCN-226(Cu) and PCN-226(Co) against cRED data.*

\begin{tabular}{lcc}
\hline & PCN-226(Cu) & PCN-226(Co)** \\
\hline Chemical formula & $\mathrm{C}_{248} \mathrm{Cu}_{4} \mathrm{~N}_{16} \mathrm{O}_{64} \mathrm{Zr}_{12}$ & $\mathrm{C}_{248} \mathrm{Co}_{4} \mathrm{~N}_{16} \mathrm{O}_{64} \mathrm{Zr}_{12}$ \\
Space group & Ibam $(\mathrm{No.} 72)$ & Ibam $(\mathrm{No.}$. 72) \\
$a(\AA)$ & $37.319(7)$ & $37.572(8)$ \\
$b(\AA)$ & $11.628(2)$ & $11.367(2)$ \\
$c(\AA)$ & $33.058(7)$ & $32.780(7)$ \\
$Z$ & 2 & 2 \\
Completeness $(\%)$ & 72.0 & 75.3 \\
Resolution $(\AA)$ & 1.15 & 1.10 \\
No. of reflections $($ all unique) & 1842 & 2140 \\
No. of reflections $\left(\mathrm{F}_{\mathrm{o}}>4 \sigma\left(\mathrm{F}_{\mathrm{o}}\right)\right)$ & 1485 & 1676 \\
Refined parameters & 135 & 135 \\
$R_{\text {int }}$ & 0.1195 & 0.1732 \\
$R_{l}$ for $\mathrm{F}_{\mathrm{o}}>4 \sigma\left(\mathrm{F}_{\mathrm{o}}\right)$ & 0.2505 & 0.2886 \\
$R_{l}$ for all data & 0.2729 & 0.3113 \\
GOOF & 2.506 & 2.900 \\
\hline
\end{tabular}

*H atoms are not included in the refinement.

** Four dataset were merged. 
Table S4. Active-site loadings and densities of PCN-226(Cu) and PCN-226(Co).

\begin{tabular}{|c|c|c|c|c|c|c|c|}
\hline \multirow{2}{*}{\multicolumn{2}{|c|}{ Co }} & \multicolumn{2}{|c|}{ ICP-OES } & \multicolumn{3}{|c|}{ Crystallographic } & \multirow[b]{2}{*}{$\begin{array}{l}\text { Active-site } \\
\text { density** } \\
\left(10^{8} \mu \mathrm{m}^{-3}\right)\end{array}$} \\
\hline & & $\begin{array}{c}\mathrm{Cu} \\
(\operatorname{mass} \%)\end{array}$ & $\begin{array}{c}\mathrm{Zr} \\
(\operatorname{mass} \%)\end{array}$ & $\begin{array}{l}\mathrm{Zr} / \mathrm{Cu} \\
\text { (molar } \\
\text { ratio) }\end{array}$ & $\begin{array}{c}\mathrm{Zr} / \mathrm{Cu} \\
(\text { molar ratio) }\end{array}$ & $\begin{array}{l}\text { Loading* } \\
\qquad(\%)\end{array}$ & \\
\hline $\begin{array}{c}\text { PCN- } \\
226(\mathrm{Cu})\end{array}$ & N/A & 3.49 & 18.97 & 3.79 & 3.00 & 79.4 & 4.68 \\
\hline $\begin{array}{c}\text { PCN- } \\
226(\mathrm{Co})\end{array}$ & 3.27 & N/A & 17.42 & 3.44 & 3.00 & 87.2 & 5.15 \\
\hline \multirow{2}{*}{\multicolumn{8}{|c|}{$\begin{array}{l}* \text { Active-site loading was calculated by comparing the experimental } \mathrm{Zr} / \mathrm{Cu} \text { ratio from } \mathrm{ICP}-\mathrm{OES} \text { results to } \\
\text { the theoretical ratio from crystallographic structural model. } \\
* * \text { Active-site density }=\text { density of crystallographic porphyrinic metal sites } \times \text { loading, assuming all the } \\
\text { porphyrinic metals are available. For PCN-226(Cu), active-site density }=5.91 \times 0.794=4.68 \times 10^{8} \mu \mathrm{m}^{-3} \text {. } \\
\text { For PCN-226(Cu), active-site density }=5.91 \times 0.872=5.15 \times 10^{8} \mu \mathrm{m}^{-3} \text {. }\end{array}$}} \\
\hline & & & & & & & \\
\hline \multicolumn{8}{|c|}{$\begin{array}{l}\text { Table S5. Comparison of the onset potential } E_{\text {onset }} \text { and half-wave potential } E_{1 / 2} \text { of as-prepared PCN- } 226 \\
\text { (M) (M= Co, Fe, } \mathrm{Zn}, \mathrm{Cu}, \mathrm{Ni}) \text { for ORR. }\end{array}$} \\
\hline \multicolumn{2}{|c|}{ Catalyst } & \multicolumn{2}{|c|}{ Loading $\left(\mathrm{mg} \mathrm{cm}^{-2}\right)$} & Electrolyte & $E_{\text {onset Vs RHE (V) }}$ & \multicolumn{2}{|c|}{$E_{1 / 2}$ vs RHE (V) } \\
\hline \multicolumn{2}{|c|}{ PCN-226(Co) } & \multicolumn{2}{|l|}{0.32} & $0.1 \mathrm{M} \mathrm{KOH}$ & 0.75 & \multicolumn{2}{|r|}{0.60} \\
\hline \multicolumn{2}{|c|}{ PCN-226(Fe) } & \multicolumn{2}{|l|}{0.32} & $0.1 \mathrm{M} \mathrm{KOH}$ & 0.70 & \multicolumn{2}{|r|}{0.58} \\
\hline \multicolumn{2}{|c|}{ PCN-226(Zn) } & \multicolumn{2}{|l|}{0.32} & $0.1 \mathrm{M} \mathrm{KOH}$ & 0.68 & \multicolumn{2}{|r|}{0.56} \\
\hline \multicolumn{2}{|c|}{$\mathrm{PCN}-226(\mathrm{Cu})$} & \multicolumn{2}{|l|}{0.32} & $0.1 \mathrm{M} \mathrm{KOH}$ & 0.63 & \multicolumn{2}{|r|}{0.55} \\
\hline \multicolumn{2}{|c|}{ PCN-226(Ni) } & \multicolumn{2}{|l|}{0.32} & $0.1 \mathrm{M} \mathrm{KOH}$ & 0.63 & \multicolumn{2}{|r|}{0.55} \\
\hline
\end{tabular}

Table S6. The onset potential $E_{\text {onset, }}$ half-wave potential $E_{1 / 2}$, and the electron transfer number $n$ of PCN221(Co), PCN-222(Co), and PCN-226(Co) in mixing with carbon black

\begin{tabular}{cccc}
\hline & $E_{\text {onset }}(\mathrm{V}$ vs RHE $)$ & $E_{1 / 2}(\mathrm{~V}$ vs RHE $)$ & $n$ \\
\hline PCN-221(Co) & 0.80 & 0.70 & 2.6 \\
PCN-222(Co) & 0.80 & 0.69 & 2.3 \\
PCN-226(Co) & 0.83 & 0.75 & 3.3 \\
\hline
\end{tabular}


Table S7. Comparison of the TOF of PCN-226(Co) with previously reported catalysts in ORR.

\begin{tabular}{ccc}
\hline Catalysts & TOF $\left(\mathrm{e} \mathrm{site}^{-1} \mathrm{~s}^{-1}\right)$ & Reference \\
\hline PCN-226(Co) & $\mathbf{0 . 1 7}$ & This work \\
Pt/C & 0.18 & This work \\
$\mathrm{Ni}_{3}(\mathrm{HITP})_{2}$ & 0.056 & 15 \\
Fe-TAPP COF aerogel & 0.25 & 16 \\
2D CAN-Pc(Fe/Co) & 0.08 & 17 \\
N-doped graphene nanoribbons & 0.08 & 18 \\
N-doped activated carbon & 0.095 & 19 \\
Fe, N-doped graphene & 0.33 & 20 \\
single-metal-site tin/nitrogen- \\
doped carbon
\end{tabular}

HITP $=$ hexaiminotriphenylene; TAPP $=5,10,15,20$-(Tetra-4-aminophenyl)porphyrin; $\mathrm{COF}=$ covalent organic framework; $\mathrm{CAN}=$ conjugated aromatic networks; $\mathrm{Pc}=$ phthalocyanines. 
Table S8. Comparison of the performance of PCN-226(Co) with previously reported electrocatalysts in rechargeable $\mathrm{Zn}$-air batteries.

\begin{tabular}{|c|c|c|}
\hline Catalysts & $\begin{array}{l}\text { Peak power density ( } \mathrm{mW} \\
\mathrm{cm}^{-2} \text { ) }\end{array}$ & Reference \\
\hline PCN-226(Co) & 133 & This work \\
\hline $\mathrm{Co}(\mathrm{bpdc})\left(\mathrm{H}_{2} \mathrm{O}\right)_{4}$ & 86.2 & 22 \\
\hline ZIF-67 derived CuCo-NC & 66.9 & 23 \\
\hline $\begin{array}{c}\mathrm{Co}(\mathrm{BDC})_{2}(\mathrm{SPDP})_{2}(\mathrm{DMF})\left(\mathrm{H}_{2} \mathrm{O}\right) \text { derived } \\
\mathrm{Co}_{9} \mathrm{~S}_{8} @ \mathrm{~N}, \mathrm{O} \text { and S-tridoped carbon }\end{array}$ & 101.5 & 24 \\
\hline $\begin{array}{c}\text { ZIF-L derived hierarchical } \mathrm{Co}_{3} \mathrm{O}_{4} \text { nano-micro } \\
\text { arrays }\end{array}$ & 75 & 25 \\
\hline $\mathrm{NiCoZn}$-ZIF derived $\mathrm{Co}_{9-x} \mathrm{Ni}_{x} \mathrm{~S}_{8} / \mathrm{NC}$ & 75 & 26 \\
\hline $\mathrm{N}, \mathrm{P}$-codoped mesoporous nanocarbon foams & 55 & 27 \\
\hline $\mathrm{N}$-doped graphene nanoribbons & 65 & 18 \\
\hline $\mathrm{N}, \mathrm{O}$-codoped graphene nanorings & 111.9 & 28 \\
\hline $\mathrm{S}, \mathrm{N}-\mathrm{Fe} / \mathrm{N} / \mathrm{C}-\mathrm{CNT}$ & 102.7 & 29 \\
\hline $\mathrm{FeN}_{\mathrm{x}} / \mathrm{C}-700-20$ & 36 & 30 \\
\hline 2D CAN-Pc(Fe/Co $)$ & 88 & 17 \\
\hline $\mathrm{Co}_{3} \mathrm{O}_{4}$ nanowire & 40 & 31 \\
\hline $\mathrm{NiFeO} @ \mathrm{MnO}_{\mathrm{x}}$ & 81 & 32 \\
\hline $\mathrm{ZnCo}_{2} \mathrm{O}_{4} \mathrm{QDs} @ \mathrm{~N}$-doped CNT & 82.3 & 33 \\
\hline
\end{tabular}

bpdc = biphenyl -4, 4'-dicarboxylic acid; $\mathrm{H}_{2} \mathrm{BDC}=1$,4-benzenedicarboxylic acid, SPDP = 4,4'-(sulfonylbis(4,1phenylene))dipyridine, $\mathrm{DMF}=\mathrm{N}, \mathrm{N}$-dimethylformamide; $\mathrm{NC}=\mathrm{N}$-doped carbons; $\mathrm{CNT}=$ carbon nanotube; $\mathrm{CAN}=$ conjugated aromatic networks; $\mathrm{Pc}=$ phthalocyanines. 


\section{Author Information}

\section{Corresponding Authors}

Haoquan Zheng - Key Laboratory of Applied Surface and Colloid Chemistry, Ministry of Education, School of Chemistry and Chemical Engineering, Shaanxi Normal University, Xi'an 710119, China; $\odot$ orcid.org/0000-0003-3869-4055;

Email: zhenghaoquan@snnu.edu.cn

Hong-Cai Zhou - Department of Chemistry and Department of Materials Science and Engineering, Texas A b'M University, College Station, Texas 77843-3255, United States; $\odot$ orcid.org/0000-0002-9029-3788;

Email: $\underline{\text { hhou@chem.tamu.edu }}$

Zhehao Huang - Department of Materials and Environmental Chemistry, Stockholm University, Stockholm SE-106 91, Sweden; $\odot$ orcid.org/0000-0002-4575-7870;

Email: zhehao.huang@mmk.su.se

\section{Authors}

Magdalena Ola Cichocka - Department of Materials and Environmental Chemistry, Stockholm University, Stockholm SE-106 91, Sweden

Zuozhong Liang - Key Laboratory of Applied Surface and Colloid Chemistry, Ministry of Education, School of Chemistry and Chemical Engineering, Shaanxi Normal University, Xi'an 710119, China

Dawei Feng - Department of Chemistry, Texas Aઐ M University, College Station, Texas 77843-3255, United States

Seoin Back - Department of Chemical and Biomolecular Engineering, Sogang University, Seoul 04107, Republic of Korea

Samira Siahrostami - Department of Chemistry, University of Calgary, Calgary, Alberta T2N1N4, Canada; $\oplus^{\text {orcid.org/0000- }}$ $\underline{0002-1192-4634}$

Xia Wang - Department of Materials and Environmental Chemistry, Stockholm University, Stockholm SE-106 91, Sweden

Laura Samperisi - Department of Materials and Environmental Chemistry, Stockholm University, Stockholm SE-106 91, Sweden

Yujia Sun - Department of Chemistry, Texas A \& M University, College Station, Texas 77843-3255, United States

Hongyi Xu - Department of Materials and Environmental Chemistry, Stockholm University, Stockholm SE-106 91, Sweden; orcid.org/0000-0002-8271-3906

Niklas Hedin - Department of Materials and Environmental Chemistry, Stockholm University, Stockholm SE-106 91, Sweden; orcid.org/0000-0002-7284-2974

Xiaodong Zou - Department of Materials and Environmental Chemistry, Stockholm University, Stockholm SE-106 91, Sweden; $\odot$ orcid.org/0000-0001-6748-6656

\section{Author Contributions}

${ }^{\nabla}$ M.O.C. and Z.L. contributed equally to this work. 


\section{References}

(1) International Organization for Standardization. Technical Committee ISO/TC 24. Particle Charac-Terization Including Sieving, P. Characterization. Determination of the Specific Surface Area of Solids by Gas Adsorption: BET Method; ISO, 2010.

(2) Feng, D.; Gu, Z.-Y.; Chen, Y.-P.; Park, J.; Wei, Z.; Sun, Y.; Bosch, M.; Yuan, S.; Zhou, H.-C. A Highly Stable Porphyrinic Zirconium Metal-Organic Framework with Shp-a Topology. J. Am. Chem. Soc. 2014, 136 (51), 17714-17717.

(3) Kabsch, W. Integration, Scaling, Space-Group Assignment and Post-Refinement. Acta Crystallogr. D Biol. Crystallogr. 2010, 66 (Pt 2), 133-144.

(4) Sheldrick, G. M. A Short History of SHELX. Acta Crystallogr. A 2008, 64 (1), 112-122.

(5) Sheldrick, G. M. SHELXT - Integrated Space-Group and Crystal-Structure Determination. Acta Crystallogr. Sect. Found. Adv. 2015, 71 (1), 3-8.

(6) Wan, W.; Hovmöller, S.; Zou, X. Structure Projection Reconstruction from Through-Focus Series of High-Resolution Transmission Electron Microscopy Images. Ultramicroscopy 2012, 115, 50-60.

(7) Kresse, G.; Furthmüller, J. Efficiency of Ab-Initio Total Energy Calculations for Metals and Semiconductors Using a Plane-Wave Basis Set. Comput. Mater. Sci. 1996, 6 (1), 15-50.

(8) Kresse, G.; Joubert, D. From Ultrasoft Pseudopotentials to the Projector Augmented-Wave Method. Phys. Rev. B 1999, 59 (3), 1758-1775.

(9) Wellendorff, J.; Lundgaard, K. T.; Møgelhøj, A.; Petzold, V.; Landis, D. D.; Nørskov, J. K.; Bligaard, T.; Jacobsen, K. W. Density Functionals for Surface Science: Exchange-Correlation Model Development with Bayesian Error Estimation. Phys. Rev. B 2012, 85 (23), 235149.

(10) Blöchl, P. E. Projector Augmented-Wave Method. Phys. Rev. B 1994, 50 (24), 17953-17979.

(11) Larsen, A. H.; Mortensen, J. J.; Blomqvist, J.; Castelli, I. E.; Christensen, R.; Dullak, M.; Friis, J.; Groves, M. N.; Hammer, B.; Hargus, C.; Hermes, E. D.; Jennings, P. C.; Jensen, P. B.; Kermode, J.; Kitchin, J. R.; Kolsbjerg, E. L.; Kubal, J.; Kaasbjerg, K.; Lysgaard, S.; Maronsson, J. B.; Maxson, T.; Olsen, T.; Pastewka, L.; Peterson, A.; Rostgaard, C.; Schiøtz, J.; Schütt, O.; Strange, M.; Thygesen, K. S.; Vegge, T.; Vilhelmsen, L.; Walter, M.; Zeng, Z.; Jacobsen, K. W. The Atomic Simulation Environment-a Python Library for Working with Atoms. J. Phys. Condens. Matter 2017, 29 (27), 273002.

(12) Nørskov, J. K.; Rossmeisl, J.; Logadottir, A.; Lindqvist, L.; Kitchin, J. R.; Bligaard, T.; Jónsson, H. Origin of the Overpotential for Oxygen Reduction at a Fuel-Cell Cathode. J. Phys. Chem. B 2004, 108 (46), 17886-17892.

(13) Back, S.; Siahrostami, S. Noble Metal Supported Hexagonal Boron Nitride for the Oxygen Reduction Reaction: A DFT Study. Nanoscale Adv. 2019, 1 (1), 132-139.

(14) Wan, W.; Sun, J.; Su, J.; Hovmöller, S.; Zou, X. Three-Dimensional Rotation Electron Diffraction: Software RED for Automated Data Collection and Data Processing. J. Appl. Crystallogr. 2013, 46 (6), 1863-1873.

(15) Miner, E. M.; Fukushima, T.; Sheberla, D.; Sun, L.; Surendranath, Y.; Dincă, M. Electrochemical Oxygen Reduction Catalysed by $\mathrm{Ni}_{3}(\text { Hexaiminotriphenylene) })_{2}$. Nat. Commun. 2016, 7 (1), 10942.

(16) Zion, N.; Cullen, D. A.; Zelenay, P.; Elbaz, L. Heat-Treated Aerogel as a Catalyst for the Oxygen Reduction Reaction. Angew. Chem. Int. Ed. 2020, 59 (6), 2483-2489.

(17) Yang, S.; Yu, Y.; Dou, M.; Zhang, Z.; Dai, L.; Wang, F. Two-Dimensional Conjugated Aromatic Networks as High-Site-Density and Single-Atom Electrocatalysts for the Oxygen Reduction Reaction. Angew. Chem. Int. Ed. 2019, 58 (41), 14724-14730.

(18) Yang, H. B.; Miao, J.; Hung, S.-F.; Chen, J.; Tao, H. B.; Wang, X.; Zhang, L.; Chen, R.; Gao, J.; Chen, H. M.; Dai, L.; Liu, B. Identification of Catalytic Sites for Oxygen Reduction and Oxygen Evolution in N-Doped Graphene Materials: Development of Highly Efficient Metal-Free Bifunctional Electrocatalyst. Sci. Adv. 2016, 2 (4), e1501122.

(19) Rybarczyk, M. K.; Gontarek, E.; Lieder, M.; Titirici, M.-M. Salt Melt Synthesis of Curved Nitrogen-Doped Carbon Nanostructures: ORR Kinetics Boost. Appl. Surf. Sci. 2018, 435, 543-551.

(20) Zitolo, A.; Goellner, V.; Armel, V.; Sougrati, M.-T.; Mineva, T.; Stievano, L.; Fonda, E.; Jaouen, F. Identification of Catalytic Sites for Oxygen Reduction in Iron- and Nitrogen-Doped Graphene Materials. Nat. Mater. 2015, 14 (9), 937-942.

(21) Luo, F.; Roy, A.; Silvioli, L.; Cullen, D. A.; Zitolo, A.; Sougrati, M. T.; Oguz, I. C.; Mineva, T.; Teschner, D.; Wagner, S.; Wen, J.; Dionigi, F.; Kramm, U. I.; Rossmeisl, J.; Jaouen, F.; Strasser, P. P -Block Single-Metal-Site Tin/Nitrogen-Doped Carbon Fuel Cell Cathode Catalyst for Oxygen Reduction Reaction. Nat. Mater. 2020, 1-9.

(22) Chen, G.; Zhang, J.; Wang, F.; Wang, L.; Liao, Z.; Zschech, E.; Müllen, K.; Feng, X. Cobalt-Based Metal-Organic Framework Nanoarrays as Bifunctional Oxygen Electrocatalysts for Rechargeable Zn-Air Batteries. Chem. - Eur. J. 2018, 24 (69), 18413-18418. 
(23) Kang, X.; Fu, G.; Song, Z.; Huo, G.; Si, F.; Deng, X.; Fu, X.-Z.; Luo, J.-L. Microwave-Assisted Hydrothermal Synthesis of MOFs-Derived Bimetallic CuCo-N/C Electrocatalyst for Efficient Oxygen Reduction Reaction. $J$. Alloys Compd. 2019, 795, 462-470.

(24) Zhao, J.-Y.; Wang, R.; Wang, S.; Lv, Y.-R.; Xu, H.; Zang, S.-Q. Metal-Organic Framework-Derived Cog S $_{8}$ Embedded in N, O and S-Tridoped Carbon Nanomaterials as an Efficient Oxygen Bifunctional Electrocatalyst. $J$. Mater. Chem. A 2019, 7 (13), 7389-7395.

(25) Zhong, Y.; Pan, Z.; Wang, X.; Yang, J.; Qiu, Y.; Xu, S.; Lu, Y.; Huang, Q.; Li, W. Hierarchical $\mathrm{Co}_{3} \mathrm{O}_{4} \mathrm{Nanno}^{-}$ Micro Arrays Featuring Superior Activity as Cathode in a Flexible and Rechargeable Zinc-Air Battery. Adv. Sci. 2019, $6(11), 1802243$.

(26) Cai, Z.; Yamada, I.; Yagi, S. ZIF-Derived Co- ${ }_{9} \mathrm{XNi}_{\mathrm{x}} \mathrm{S}_{8}$ Nanoparticles Immobilized on N-Doped Carbons as Efficient Catalysts for High-Performance Zinc-Air Batteries. ACS Appl. Mater. Interfaces 2020, 12 (5), 5847-5856.

(27) Zhang, J.; Zhao, Z.; Xia, Z.; Dai, L. A Metal-Free Bifunctional Electrocatalyst for Oxygen Reduction and Oxygen Evolution Reactions. Nat. Nanotechnol. 2015, 10 (5), 444-452.

(28) Hu, Q.; Li, G.; Li, G.; Liu, X.; Zhu, B.; Chai, X.; Zhang, Q.; Liu, J.; He, C. Trifunctional Electrocatalysis on DualDoped Graphene Nanorings-Integrated Boxes for Efficient Water Splitting and Zn-Air Batteries. Adv. Energy Mater. 2019, 9 (14), 1803867.

(29) Chen, P.; Zhou, T.; Xing, L.; Xu, K.; Tong, Y.; Xie, H.; Zhang, L.; Yan, W.; Chu, W.; Wu, C.; Xie, Y. Atomically Dispersed Iron-Nitrogen Species as Electrocatalysts for Bifunctional Oxygen Evolution and Reduction Reactions. Angew. Chem. Int. Ed. 2017, 56 (2), 610-614.

(30) Han, S.; Hu, X.; Wang, J.; Fang, X.; Zhu, Y. Novel Route to Fe-Based Cathode as an Efficient Bifunctional Catalysts for Rechargeable Zn-Air Battery. Adv. Energy Mater. 2018, 8 (22), 1800955.

(31) Lee, D. U.; Choi, J.-Y.; Feng, K.; Park, H. W.; Chen, Z. Advanced Extremely Durable 3D Bifunctional Air Electrodes for Rechargeable Zinc-Air Batteries. Adv. Energy Mater. 2014, 4 (6), 1301389.

(32) Cheng, Y.; Dou, S.; Veder, J.-P.; Wang, S.; Saunders, M.; Jiang, S. P. Efficient and Durable Bifunctional Oxygen Catalysts Based on $\mathrm{NiFeO} @ \mathrm{MnO}_{\mathrm{x}}$ Core-Shell Structures for Rechargeable $\mathrm{Zn}$-Air Batteries. ACS Appl. Mater. Interfaces 2017, 9 (9), 8121-8133.

(33) Liu, Z.-Q.; Cheng, H.; Li, N.; Ma, T. Y.; Su, Y.-Z. ZnCo $\mathrm{Zn}_{4}$ Quantum Dots Anchored on Nitrogen-Doped Carbon Nanotubes as Reversible Oxygen Reduction/Evolution Electrocatalysts. Adv. Mater. 2016, 28 (19), 3777-3784. 